\title{
17. STRUCTURAL EVOLUTION OF UPPER LAYER 2, HOLE 896A ${ }^{1}$
}

\author{
Gregory D. Harper ${ }^{2}$ and Paola Tartarotti ${ }^{3}$
}

\begin{abstract}
An analysis of the state of stress in the upper ocean crust shows that high hydrostatic pore-fluid pressures will result from the thick overlying water column, providing that the upper crust is sufficiently permeable. High pore-fluid pore pressures will result in very low effective stresses in the upper ocean crust. Such conditions favor deformation by formation of extension fractures and mixed mode (combined extension and shear) fractures rather than by frictional sliding on faults. High pore-fluid pressures are considered very likely to have produced many of the structures in Hole 896A, including jigsaw-puzzle breccias and associated vein networks, cement-supported breccias, and fibrous veins. These structures record an overall volume increase, and their geometry and offset markers indicate formation as extensional fractures or, in some cases, mixed mode fracturing. The geometry and textures of jigsaw-puzzle breccias and associated vein networks suggest formation by longitudinal (axial) splitting, a type of brittle rock failure that occurs in rock deformation experiments done under stress conditions similar to those in the upper ocean crust $\left(\sigma_{2}^{\prime}\right.$ and $\left.\sigma_{3}^{\prime} \leq 0\right)$. Breccias can form by disaggregation during volume increase associated with extension or mixed mode fractures. The textures of many breccias formed in this way are very similar to those of sedimentary breccias and thus the sedimentary vs. tectonic origin of many breccias in the drill core is uncertain, especially because the margins of the breccias are not usually preserved in core. The fibrous veins generally postdate jigsaw-puzzle breccias and vein networks. They probably formed by repeated cycles of hydrofracturing and sealing of fractures (crack-seal mechanism). The extension directions indicated by both fibrous and nonfibrous veins are highly variable in orientation, even within a single piece, and vein networks suggest simultaneous extension in several directions. In addition, small faults having fibrous slickensides occurring below $334 \mathrm{~m}$ below seafloor indicate normal, reverse, and oblique slip. The style of brittle deformation observed in Hole 896A should produce microseismicity characterized by a nonuniform stress field and non-double-couple earthquakes. Such microseismicity characterized geothermal activity in the post-rifting stage at Krafla, Iceland.
\end{abstract}

\section{INTRODUCTION}

Remarkably few structures interpreted to be tectonic in origin have been described from extrusive rocks sampled by the Deep Sea Drilling Project (DSDP) and Ocean Drilling Project (ODP). This is surprising considering that abundant ridge-parallel fissures and faults are evident on mid-ocean ridges (e.g., Macdonald, 1983). This structural grain must be present in at least the upper few hundred meters of the ocean crust as evident, for example, from strong seismic velocity anisotropy (McDonald et al., 1994). Several possible explanations for the paucity of structures include the following: (1) structures have only recently been systematically studied in drill cores from ocean crust, beginning with Leg 118 ; (2) highly fractured intervals such as fault zones are unlikely to be recovered, especially considering the generally low recovery rates; (3) steeply dipping structures have a low probability of being sampled by a vertical drill hole; and (4) products of brittle deformation, such as breccias, can be very difficult to distinguish from those produced by sedimentary processes, especially because the dip of breccia zones and their contacts with adjacent rock types are not generally evident in core.

Structures observed in core from the upper ocean crust consist primarily of veins, fractures, breccias, and rare chilled dike margins (see summary in Agar, 1994). Except for drill holes in gabbros, fault rocks appear to be rare and include submillimeter- to centimeter-scale cataclastic zones and possibly some breccias (Choukroune, 1977; Agar, 1990, 1991, 1994; Dick, Erzinger, Stokking, et al., 1992; Gillis, Mével, Allan, et al., 1993; A1t, Kinoshita, Stokking, et al., 1993). It is likely, however, that faults have been drilled quite often, but that fault

'Alt, J.C., Kinoshita, H., Stokking, L.B., and Michael, P.J. (Eds.), 1996. Proc. ODP, Sci. Results, 148: College Station, TX (Ocean Drilling Program).

2Department of Geological Sciences, State University of New York, Albany, NY 12222,U.S.A.GDH@csc.albany.edu

'Dipartimento di Geologia, Paleontologia e Geofisica, Università delgi Studi di Padova, via Giotto I, I-37137 Padova, Italy. rocks were not recovered because of a combination of the high density of fractures typically associated with faults (e.g., Scholtz, 1990) and use of rotary drilling techniques. In many cases, the significance of some structures may not have been recognized. For example, abundant fibrous veins in Hole 896A (Alt, Kinoshita, H., Stokking, et al., 1993) and the upper part of Hole 504B (Agar, 1990; P. Tartarotti, unpubl. data, 1994) have characteristics suggesting formation by the crack-seal mechanism (i.e., incremental growth of fibers during cyclic hydrofracturing; Agar, 1990; Tartarotti et al., this volume). Breccias in DSDP and ODP drill cores from the upper ocean crust have generally been considered to have formed on the seafloor as sedimentary accumulations or hyaloclastites, but the characteristics of these breccias do not rule out a tectonic origin (Agar, 1994).

Faults and fractures in the upper ocean crust will be closely associated with fluid flow. The close association of fluids and active faults has been well documented on land from changes in ground water flow associated with earthquakes and fault creep (e.g., Sibson, 1981a; Bolt, 1993; Rudnicki et al., 1993) and is also evident at midocean ridges from the linear arrangement of hot springs along faults or fissures (e.g., Nehlig, 1993). In crystalline rocks having very low intracrystalline porosity, brittle deformation can result in localized zones of relatively high permeability. Such high fracture permeability is obvious in the case of extension fractures (e.g., fissures), which are open and fluid filled, but faults will also generally have high permeability due to the dilatancy of microcracks and the highly fractured damage zones associated with faults (Scholz, 1990). Permeability can be highly variable over time, however, because of clogging of cracks by hydrothermal mineral precipitation which can later be reopened by renewed fracturing. Permeability may also be spatially variable within a fault zone; for example, clay-rich fault gouge may be impermeable whereas the surrounding damage zone may be highly permeable.

In this paper we discuss the structural evolution of the extrusive sequence sampled in Hole 896A, located south of the Cocos Ridge in the eastern Pacific (Fig. 1), with emphasis on brittle deformation and 


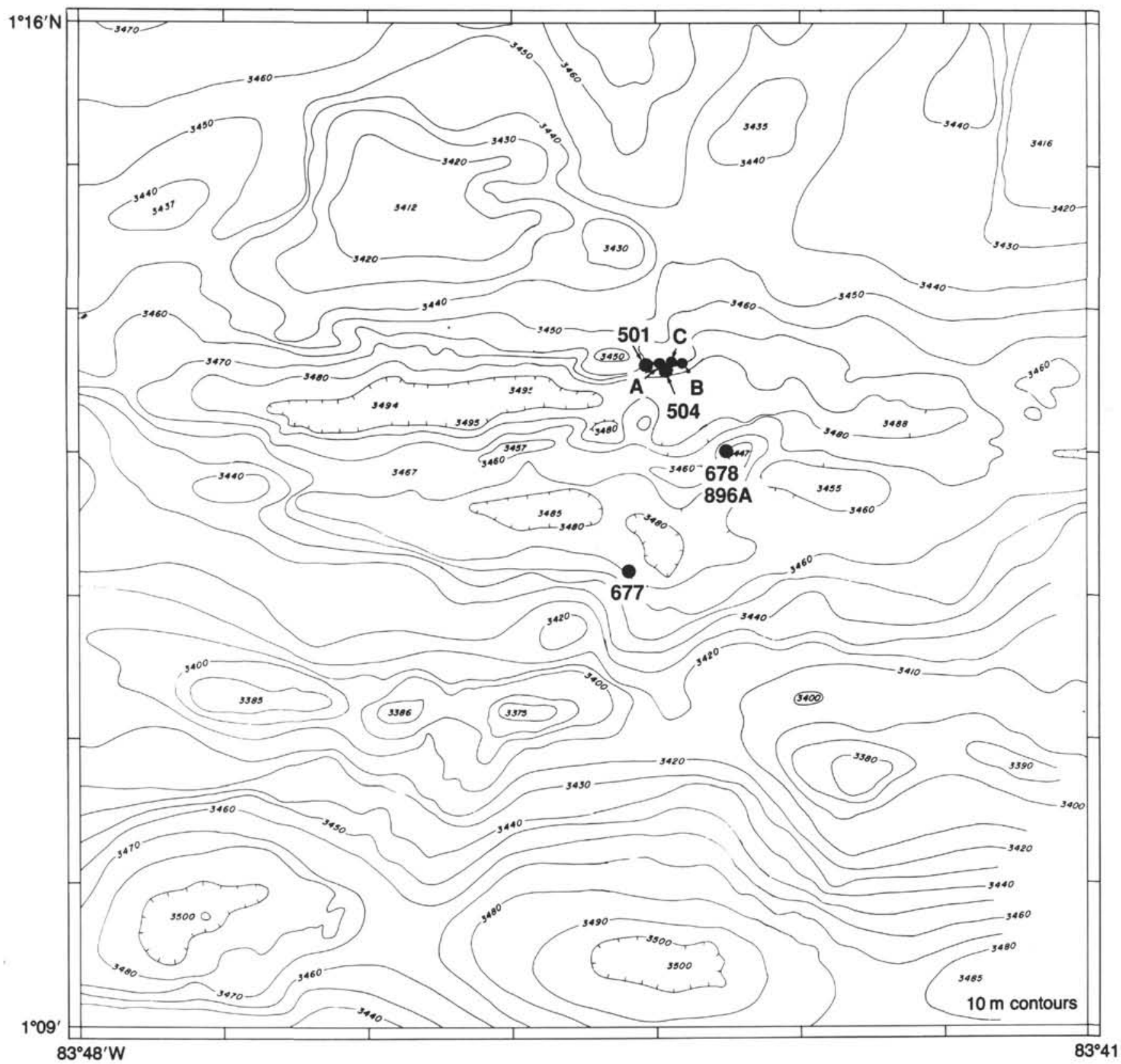

Figure 1. Site location map.

its relation to fluids and hydrothermal mineral deposition. We first present an analysis of the state of stress in the upper oceanic crust in order to evaluate the style of brittle deformation predicted by rock mechanics. A particularly important point is that if the crust is permeable, the deep water column produces high pore-fluid pressures. It is well known that such high pore-fluid pressures have a dramatic effect on rock strength and can change the style of brittle failure from faulting to formation of extension fractures (hydrofracturing). We also examine and discuss the origin of breccias and associated vein networks observed in Hole 896A and attempt to infer a tectonic vs. sedimentary origin. Finally, the geometry, relative timing, and conditions of formation of the crack-seal veins are discussed.

\section{PORE-FLUID PRESSURES AND FRACTURING IN THE UPPER OCEANIC CRUST}

\section{Mechanics of Hydrofracturing in Ocean Crust}

In extensional environments such as mid-ocean ridges, the maximum and minimum principal stresses $\left(\sigma_{1}\right.$ and $\left.\sigma_{3}\right)$ are generally vertical and horizontal, respectively (Fig. 2A). The stress on a planar surface can be resolved into a component normal to the fault $\left(\sigma_{f}=\right.$ normal stress), which in this example acts to push rocks on either side of the fault together and thus inhibits sliding, and a component parallel to the fault ( $\tau_{f}=$ shear stress) which favors sliding. The shear and 
A

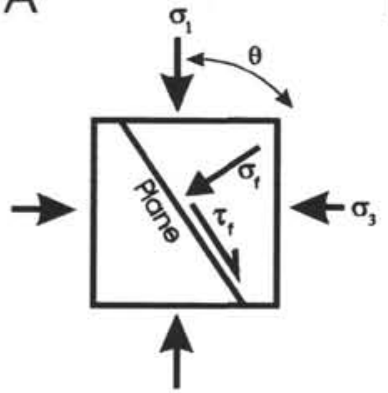

Figure 2. Stress on a plane and its representation on a Mohr diagram. $\sigma_{f}=$ normal stress on plane, $\tau_{f}=$ shear stress on plane.
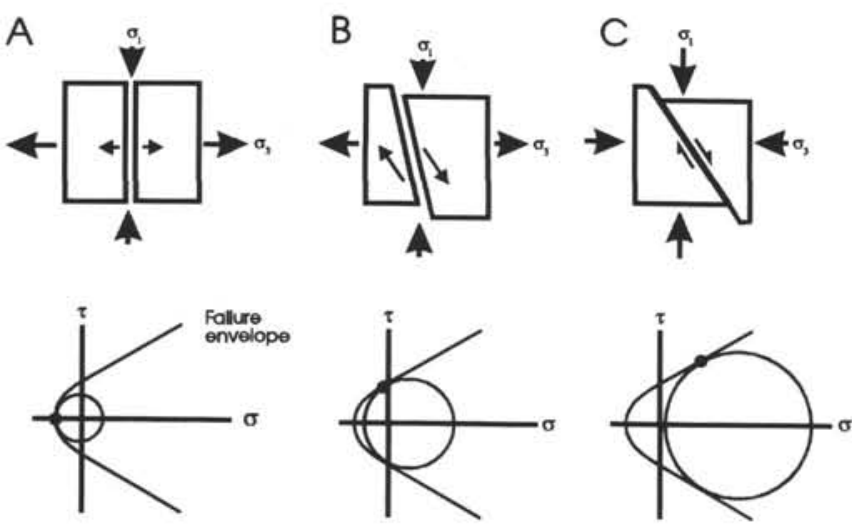

Figure 3. Failure of homogeneous, unfractured rock at increasing levels of differential stress $\left(\sigma_{1}-\sigma_{3}\right)$. The Mohr circle shows the state of stress, and the dot represents the stress state on plane of failure. A. Extension fracture, B. Mixed mode fracture. C. Fault.

normal stresses acting on any planar surface in the volume of rock are most easily represented by a plot of shear stress $(\tau)$ vs. normal stress $(\sigma)$, where the stress state on an individual plane will plot as a point (Fig. 2B). On this diagram (Mohr diagram), principal stresses plot on the abscissa because, by definition, there are no shear stresses on planes parallel or normal to a principal stress. For simplicity we will deal only in two-dimensional stress, in which case all planar surfaces in the rock volume lie on the perimeter of a circle containing $\sigma_{1}$ and $\sigma_{3}$. A plane in the rock volume whose pole lies at an angle $\theta$ to $\sigma_{1}$ (Fig. 2A) plots at an angle of $2 \theta$ from $\sigma_{1}$ on the Mohr diagram (Fig. $2 \mathrm{~B})$. Note that positive and negative values on the abscissa correspond to compressive and tensional stresses, respectively. Beneath a mid-ocean ridge, $\sigma_{1}$ and $\sigma_{3}$ will be compressive as a result of the weight of the overlying rock and water column, so that the stress state will be similar to that shown in Figure 2.

At low temperatures and pressures, mafic rocks generally fail in a brittle manner either by faulting or by formation of extension fractures (oriented normal to $\sigma_{3}$; Patterson, 1978). When homogenous isotropic rocks are put under differential stress $\left(\sigma_{1}-\sigma_{3}\right)$, extension fractures form when $\sigma_{3}$ is tensional (Fig. $3 \mathrm{~A}$ ), whereas faulting occurs when both $\sigma_{1}$ and $\sigma_{3}$ are compressive (Fig. 3C). A type of failure transitional between extension fractures and faulting occurs where rocks on the two sides of a fracture move both laterally and apart (Fig. 3B), variably known as "mixed mode fracturing," "hybrid jointing," or "dilational faulting" (e.g., Hancock et al., 1987; Twiss and Moores, 1992). Extension occurs across the fracture in the extension fracture as well as in the dilational fault because the normal stress across the fracture is tensional, whereas across a (nondilational) fault the normal stress is compressional and thus presses the two

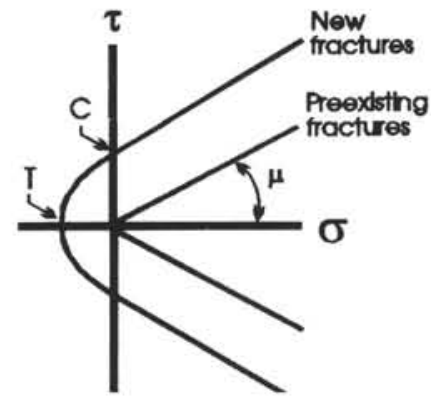

Figure 4. Failure envelopes for formation of new fractures and sliding on preexisting fractures. $T=$ tensile strength, $C=$ cohesion, $\mu=$ coefficient of friction.

sides together. The stress conditions and orientation of fractures can be readily shown on a Mohr diagram as a failure envelope (Fig. 3AC). Failure occurs when differential stress is sufficiently large to cause the Mohr circle to intersect the failure envelope (determined experimentally for homogeneous isotropic rock). Note that extensional fractures and dilational faults can occur only when the differential stress $\left(\sigma_{1}-\sigma_{3}\right)$ is small and $\sigma_{3}$ is tensional. Also, the differential stress needed for failure by faulting must be progressively higher for increasing $\sigma_{3}$ (i.e., for increasing depth in the earth in absence of pore fluid). A different failure envelope has been found for preexisting fractures (i.e., displacement on preexisting faults); lower differential stress is needed to cause sliding on an optimally oriented preexisting fault than for formation on a new fault (Fig. 4). Because the failure envelope for preexisting faults is linear and essentially passes through the origin, it implies that preexisting faults have no cohesion and that only sliding on preexisting faults should occur, provided the faults are favorably oriented $\left(\sim 15^{\circ}-60^{\circ}\right.$ to $\sigma_{1}$; Donath, 1961 ; Twiss and Moores, 1992). Extension fractures can still form, however, if the preexisting fractures are unfavorably oriented or if there is some cohesion across the fault due to surface roughness or cementation by hydrothermal minerals. The failure envelope for preexisting faults is a good fit for nearly all rock types, corresponding to a slope of $\sim 0.75$, except at low effective stresses where there is considerable scatter due to variations in cohesion related to surface roughness (Byerlee, 1978). Thus, it should be kept in mind that the failure envelopes are only approximate fits of the experimental data, but they do provide a good criterion for a first approximation of the strength of the upper crust.

If pores (including fractures) in a rock are interconnecting, the pore fluid will be under pressure from the weight of the overlying fluid, and this pressure will act to push against the walls of the pores (i.e., in the opposite direction to the pressure from the rock column). The pore-fluid pressure thus reduces the normal stress on a fault but does not affect the shear stress, resulting in a dramatic weakening of the rock. The effect of adding a pore fluid under pressure to a rock mass at depth is shown on a Mohr diagram in Figure 5. The Mohr circle shifts to the left but does not change size (i.e., the shear stresses stay the same); these lowered principal stresses are called the "effective principal stresses" $\left(\sigma_{1}{ }^{\prime}=\sigma_{1}-P\right.$, and $\sigma_{3}{ }^{\prime}=\sigma_{3}-P$, where $P=$ porefluid pressure). The addition of a pore fluid under pressure may cause a rock to fracture (the Mohr circle may shift to the left sufficiently to intersect the failure envelope). Moreover, extension fractures may form, providing the rock is under small differential stress (small Mohr circle) and a sufficiently high pore-fluid pressure is present; such extension fracturing induced by the presence of a pore-fluid pressure is known as "hydrofracturing" or "hydraulic fracturing." Thus, the presence of pore-fluid pressure makes formation of extension fractures by hydrofracturing possible at virtually any depth in the crust provided fluid pressures are sufficiently high. Hydrofracturing is commonly induced in drill holes by pumping water into a sealed- 


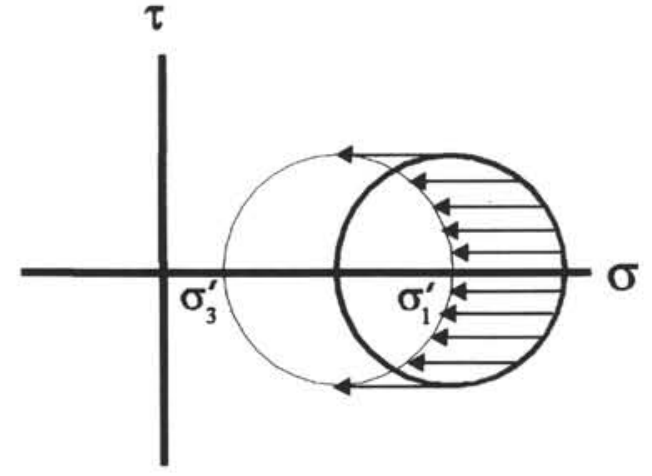

Figure 5. Effect of adding a pore fluid under pressure. $\sigma_{1}{ }^{\prime}$ and $\sigma_{3}{ }^{\prime}$ are effective principal stresses, defined as $\sigma_{1}{ }^{\prime}=\sigma_{1}-P$ and $\sigma_{3}{ }^{\prime}=\sigma_{3}-P$, where $P=$ pore-fluid pressure.

off section of the hole until the rock fractures; this is done to increase permeability (e.g., to enhance hydrocarbon recovery) or to measure principal stress directions from the orientation of resulting extension fractures. Evidence for hydrofracturing in nature includes crack-seal veins, such as those observed in core from Hole 896A, which have been interpreted to form by repeated cycles of fracturing and mineral precipitation (Ramsay, 1980).

Sibson (1981a, 1981b) showed that pore-fluid pressures are sufficiently high in the upper part of the crust to cause hydrofracturing, at least in areas undergoing normal or strike-slip faulting. Hydrostatic pore-fluid pressures are those that result solely from the weight of the overlying pore fluids in addition to any water mass overlying the crust. Hydrostatic pore-fluid pressures will prevail providing the entire rock mass is sufficiently permeable and open to the surface. Porefluid pressures can be higher or lower than hydrostatic if a rock mass is sealed by an overlying impermeable cap. In the area of Hole 504B, sediments form an impermeable lid, and the measured pore-fluid pressures in the extrusive sequence are slightly $(\sim 3 \%)$ lower than hydrostatic (Anderson and Zoback, 1982).

Except where there is a very high sedimentation rate or recent sheet flows that may form an impermeable seal, hydrostatic pressures should prevail in the extrusive sequences at mid-ocean ridges because of high porosity and permeability resulting from interpillow voids, cooling fractures, and tectonic fractures such as fissures. High porosities are characteristic of Layers $2 \mathrm{a}(30 \%-40 \%)$ and $2 \mathrm{~b}(\sim 10 \%$; e.g., Carlson and Herrick, 1990), and high porosities and permeabilities have been inferred from dual laterolog (DLL) logs and packer experiments in Hole 504B (Becker et al., 1989). Layers 2c and 3, however, have much lower inferred porosities $(<5 \%$; Carlson and Herrick, 1990), and the sheeted dike complex in Hole 504B has very low bulk porosities and permeabilities (Becker et al., 1989). Thus the pore-fluid pressures beneath the extrusive sequence may be lithostatic or intermediate between hydrostatic and lithostatic. Hydrostatic pore-fluid pressures may prevail within fractures in Layers $2 \mathrm{c}$ and 3 provided the fractures are interconnecting. Interconnecting fractures are likely considering the variable orientations and abundance of open fractures (average $\sim 20$ per $\mathrm{m}$ ) evident from downhole Formation MicroScanner (FMS) and DLL logs for Hole 504B (Pezard and Becker, this volume; Dilek et al., chapter 16, this volume).

The hydrostatic fluid pressure will be $P=\rho_{w} g z$ where $\rho_{w}$ is the density of water, $g$ is the acceleration due to gravity, and $z$ is the depth below the surface. On the continents, the ratio $(\lambda)$ of hydrostatic porefluid pressure to the vertical load from the rock column (lithostatic pressure $=\sigma_{1}=\rho_{r} g z$, where $\rho_{r}$ is bulk rock density) is

$$
\lambda=\frac{\rho_{w} g z}{\rho_{r} g z}=\frac{\rho_{w}}{\rho_{r}}=\sim 0.4,
$$

assuming $\rho_{r}=2.6 \mathrm{~g} / \mathrm{cm}^{3}$ for continental crust. At mid-ocean ridges, hydrostatic pressures in the upper few kilometers of the crust will be much higher at a given depth because of the additional weight of the

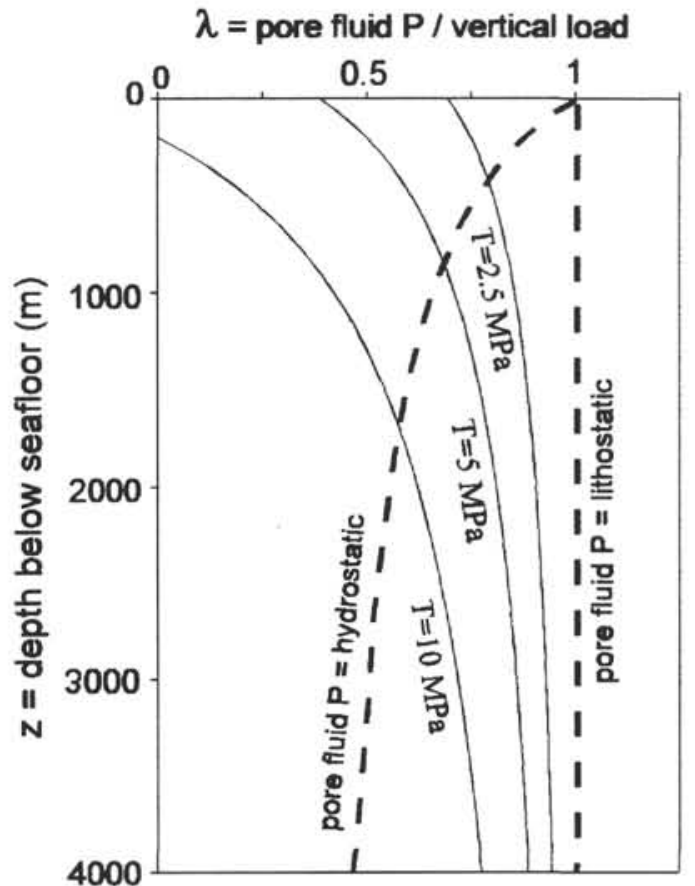

Figure 6. Curves delimiting the maximum depth for hydrofracture in a brittle crust underlying a column of water $2.5 \mathrm{~km}$ deep. Hydrofracturing occurs to the right of each curve. Curves are shown for three different assumed values of tensile strength $T$ using Equation (3) and a rock density of $2.8 \mathrm{~g} / \mathrm{cm}^{3}$. The middle curve ( $T=5 \mathrm{MPa}$ ) is considered the most likely, whereas the right and left curves correspond to the estimated lower and upper limits of tensile strength of the upper ocean crust ( $T=2.5$ and $10 \mathrm{MPa}$, respectively).

overlying water column, resulting in conditions highly favorable for hydrofracturing. The hydrostatic pressure in the ocean crust will be $\rho_{w} g(z+h)$, where $h$ is the water depth and $z$ is depth below the seafloor. The vertical load will result from the weight of the column of rock $\left(\rho_{r} g z\right)$ plus the weight of the overlying water column $\left(\rho_{n} g h\right)$. Thus the ratio $(\lambda)$ of the hydrostatic to lithostatic pressure will be

$$
\lambda=\frac{\rho_{w} g(z+h)}{\rho_{r} g z+\rho_{w} g h}=\frac{\rho_{w}(z+h)}{\rho_{r} z+\rho_{w} h} .
$$

A plot of $\lambda$ vs. depth below the seafloor is shown in Figure 6, assuming a bulk rock density of $\rho_{r}=2.8 \mathrm{~g} / \mathrm{cm}^{3}$ for upper ocean crust. The ratio is essentially 1 (i.e., hydrostatic $=$ lithostatic) immediately below the seafloor because of the thin rock column. Because the rock is $\sim 3$ times more dense than water, lithostatic pressure increases much more rapidly than hydrostatic pressure with depth, resulting in a rapid reduction of $\lambda$.

The maximum depth for hydrofracturing $\left(z_{\max }\right)$ as a function of $\lambda$ can be calculated from the failure criterion for extensional fracturing of intact homogeneous rock, given by $\sigma_{3}{ }^{\prime}=-T$ where $T$ is the tensile strength of the rock, combined with the maximum differential stress for extension fracturing, given by $\sigma_{1}^{\prime}-\sigma_{3}^{\prime}=4 T$ (Secor, 1965). Combining these two equations, and recalling $\sigma_{1}{ }^{\prime}=\sigma_{1}-P=\left(\rho_{r} g z+\rho_{w} g h\right)$ $-P$, yields the following relationship between $\lambda$ and $z_{\max }$ :

$$
\lambda=1-\frac{3 T}{\left(\rho_{r} g z_{\max }+\rho_{w} g h\right)} .
$$

The maximum depth of hydrofracturing is shown in Figure 6 by three curves corresponding to tensile strengths of $2.5,5$, and $10 \mathrm{MPa}$ (curve 2 is considered to be the best estimate). The intersection of these curves with the hydrostatic curve gives the predicted maximum depth of hydrofracturing ( $~ 850 \mathrm{~m}$ for curve 2$)$, assuming hydrostatic pore-fluid pressures. It is evident from Figure 6 that the estimated 


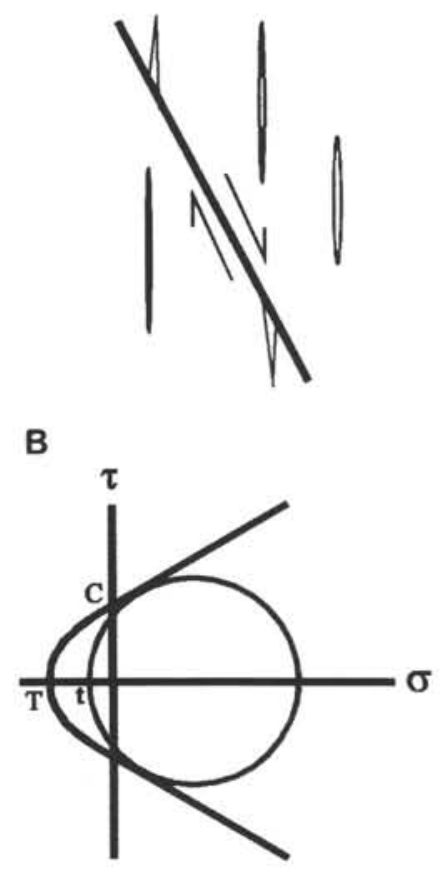

C

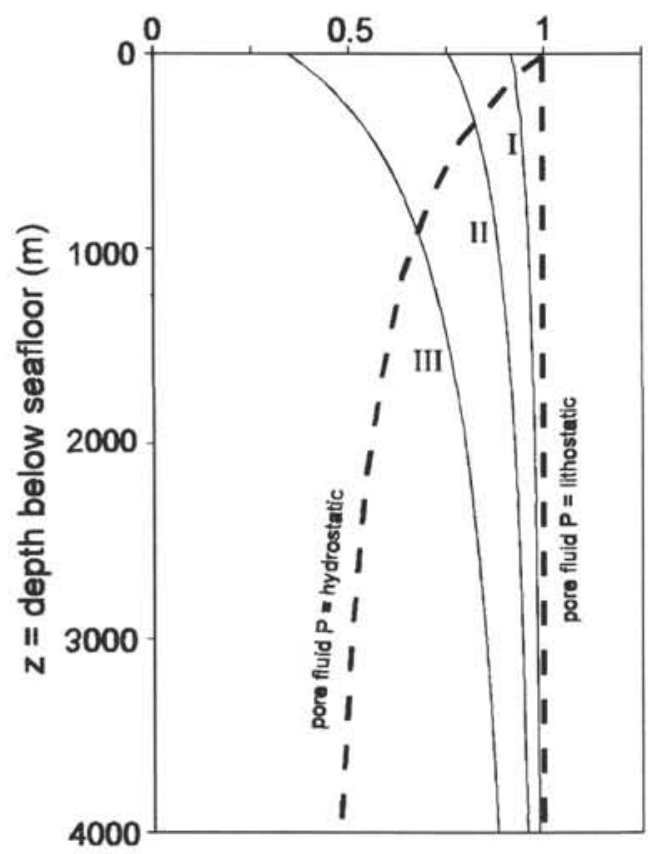

Figure 7. A. Hydrofracturing associated with a normal fault (Sibson, 1981a, 1981b). B. Critical stress condition for simultaneous shear failure on a preexisting fault, having cohesion $C$, and reopening of preexisting extension fractures having tensile strength $t$. C. Curves corresponding to simultaneous shear failure and reopening of extension fractures in brittle crust beneath $2.5 \mathrm{~km}$ of water. Area above and to the right of each curve delimits the field for potential simultaneous normal faulting and hydrofracturing. Curves were calculated using the failure criterion shown in $\mathrm{B}$ and given in Equation 5 with $\rho_{r}=2.8 \mathrm{~g} / \mathrm{cm}^{3}$ and $K=4$ $(\mu=0.75)$. The three curves correspond to different assumed values of cohesion $C(1,2.5$, and $5 \mathrm{MPa}$ for curves I, II, and III, respectively) and tensile strength of preexisting extension fractures $t(0.5 \mathrm{MPa}$ for curve I, $1 \mathrm{MPa}$ for curves II and III). maximum depth of hydrofracturing is strongly dependent on the assumed value for $T$, which is based on experimental work. Measured tensile strengths for crystalline rocks are generally between 10 and 30 MPa when measured on small homogeneous specimens (Rummel, 1987), but are considerably less when larger samples are used. For example, Rummel (1987) reports that the tensile strength of granite is $16.6 \mathrm{MPa}$ for a minicore measured in the lab, but it is $\sim 13.5 \mathrm{MPa}$ for a $1 \mathrm{~m}^{3}$ block and only $\sim 7 \mathrm{MPa}$ in a deep borehole. This dependence on sample size is apparently due to the larger probability of longer preexisting microcracks occurring in the sample. The tensile strength of a rock is also likely to be $\sim 50 \%$ lower than values measured experimentally because of time-dependent (subcritical) crack growth that precedes catastrophic failure (Etheridge, 1983), a process which is greatly enhanced by elevated temperature and the presence of water (Anderson and Grew, 1977; Atkinson and Meredith, 1987). Even though the tensile strength of the upper oceanic crust is rather poorly constrained, it is clear that hydrostatic pressures are sufficiently high in the upper several hundred meters to cause failure by hydrofracturing. Hydrofracturing could occur at greater depths than those given by the curves, but it would require pore-fluid pressures higher than hydrostatic. Hydrofracturing could be inhibited in the upper several hundred meters, however, if pore-fluid pressures were below hydrostatic as a result of an impermeable barrier. Such "underpressuring" has been observed in the extrusive sequence at 504B, which is sealed by overlying sediments, but it is important to note that the measured pore-fluid pressures were only $3 \%$ below hydrostatic (Anderson and Zoback, 1982).

The mode of failure in the uppermost ocean crust, evident from observations at mid-ocean ridges, includes faulting as well as fissuring (extension fractures) (e.g., Macdonald, 1983). That extensive ridge-parallel fracturing extends to depths of at least several hundred meters is suggested by very strong seismic anisotropy (McDonald et al., 1994). Sibson (1981b) notes that fissuring is also commonly observed in association with normal faults on land and has discussed evidence from exhumed faults for hydrofracturing associated with normal faulting (Fig. 7A). Although the predicted mode of failure in the upper oceanic or continental crust is hydrofracturing rather than faulting, fault slip initiated below the zone of hydrofracturing can propagate into the upper crust as evident, for example, from surface breakage on normal faults produced during historical earthquakes having epicenters $5-10 \mathrm{~km}$ deep. Figure $7 \mathrm{~B}$ graphically shows the failure criterion proposed by Sibson (1981a, 1981b) for simultaneous reopening of extension fractures and slip on an associated preexisting fault. For normal faulting, this failure criterion is represented by the following equation:

$$
\sigma_{1}(1-\lambda)=3 K^{1 / 2} C-K t,
$$

where $t=$ tensile strength of preexisting fractures (i.e., stress needed to reopen an extension fracture), $C=$ cohesion of the fault, and $K=$ $\left[(1+\mu)^{1 / 2}+\mu\right]^{2}=4$ for $\mu=0.75$. Substituting $\sigma_{1}=\rho_{r} g z+\rho_{w} g h$ and rearranging yields

$$
\lambda=1-\frac{3 K^{1 / 2} C-K t}{\rho_{r} g z+\rho_{w} g h} .
$$

The largest uncertainty in this failure criterion is the value for cohesion. Experimental work suggests that preexisting faults have very low cohesion (Byerlee, 1978), probably less than $1 \mathrm{MPa}$ unless there is extensive cementation, in which case cohesion may approach that of an intact rock ( $10 \mathrm{MPa}$; Sibson, 1981b). Figure 7C shows three curves, corresponding to different assumed values of $C$ and $t$, for the maximum depth at which both slip on a normal fault and reopening of extension fractures can occur for a rock column having a bulk rock density $\rho_{r}=2.8 \mathrm{~g} / \mathrm{cm}^{3}$. For this failure criterion and assuming hydrostatic pore-fluid pressures, hydrofracturing will accompany faulting at depths shallower than the intersection of each curve with the hydrostatic curve, which is at a depth of approximately $300 \mathrm{~m}$ for the preferred assumed values of $C$ and $t$ (curve II).

In summary, hydrofracturing with or without associated faulting should occur to depths of at least $\sim 500 \mathrm{~m}$ under hydrostatic pore-fluid pressures, provided the crust is sufficiently permeable (considered very likely for Layers $2 a$ and $2 b$ ). Faults that cut through the extrusive sequence should also be associated with reopening of hydrofractures. Pore fluids in the extrusive sequence at mid-ocean ridges should generally be under hydrostatic pressure because of high porosity and permeability, but they may be lower or higher than hydrostatic if the crust is sealed by sediments or massive flows. Thus, no unusual con- 
ditions are necessary to produce hydrofracturing, believed necessary to produce the crack-seal veins and possibly vein networks and jigsaw-puzzle breccias observed in core from Hole 896A (discussed below and in Tartarotti et al., this volume). It is difficult to predict whether conditions will be favorable for hydrofracturing in rocks below the extrusive sequence, due to the large uncertainties in tensile strength, the very low porosities and permeabilities such as those measured in the sheeted dike complex of Hole 504B, and whether fractures at these greater depths are interconnected.

\section{Hydrofracturing and Mineral Precipitation}

Fluid pressures can vary substantially during hydrothermal circulation. Bruton and Helgeson (1982) have considered the effects on mineral solubility due to varying pressures between hydrostatic and lithostatic in hydrothermal systems. For many minerals, such as quartz, that have a positive pressure dependence on their solubility, a sudden drop in fluid pressure will cause supersaturation, generally resulting in precipitation. Calcite is a notable exception and, because it has a negative pressure dependence on solubility, will become supersaturated with a sudden increase in fluid pressure.

Hydrofracturing provides a mechanism for a sudden change in fluid pressure and may thus be a mechanism for mineral precipitation as veins or cement in breccias. Fractures initiate at flaws in the rock and grow by propagation (e.g., Pollard and Aydin, 1988), generally occurring by short periods of rapid propagation followed by longer periods during which fluids flow into the fracture. The fractures propagate at a rate higher than the velocity of the fluid entering the crack, resulting in an instantaneous fluid pressure drop inside the crack (Phillips, 1972; Etheridge et al., 1984). For as long as the fluid in the crack is under reduced pressure, any mineral that was in equilibrium with the fluid and that has a positive pressure dependence of its solubility will become supersaturated. This drop in fluid pressure associated with fracture opening can result in mineral precipitation, with the end product being a vein. Because the solubility of minerals in aqueous fluid is generally low, filling of even a microfracture requires that either a large volume of fluid passed through the fracture or that ions were supplied from the wall rocks by diffusion.

\section{BRECCIAS AND VEIN NETWORKS}

\section{Sedimentary vs. Tectonic Origin of Breccias}

Breccias are a minor, but significant component of the drill cores from extrusive rocks of the oceanic crust. They have been previously interpreted as having formed on the surface as hyaloclastites or talus (e.g., Robinson et al., 1979), including many of the breccias of Hole 896A (Alt, Kinoshita, Stokking, et al., 1993). The breccias described from DSDP Holes 417D and 418A are very similar to those from Hole $896 \mathrm{~A}$, and were not considered to be related to faulting based on such features such as abundant glass in the matrix, freshness of the rocks, and the preservation of delicate structures in glassy selvages (Robinson et al., 1979). It is often difficult to distinguish sedimentary from tectonic breccias (Agar, 1994; Barany and Karson, 1989), especially in drill core, and none of the criteria cited by Robinson et al. (1979) disproves a genetic association with faulting (Agar, 1994). For example, breccias having textures similar to "sedimentary" breccias of Robinson et al. (1979) occur in the sheeted dikes of Hole 504B (Dick, Erzinger, Stokking, et al., 1992) and in gabbros from Hole 735B (Dick et al., 1991) where a surficial origin is not tenable. The distinction between tectonic and sedimentary breccias may be especially difficult in the shallow ocean crust because of the following: (1) tectonic breccias produced during dilational faulting are likely to show evidence for an increase in pore volume combined with a lack of evidence for frictional wear, thus texturally resembling sedimentary breccias and (2) talus breccias formed at the base of a fault scarp are likely to contain clasts of fault rocks showing cataclastic textures. For example, Barany and Karson (1989) describe breccias collected by submersible along the Clipperton Fracture Zone that contain deformed clasts set in a matrix of clay- and silt-size fragments consisting of minerals, altered glass, and clay; in drill core, these rocks would probably be interpreted as in situ fault breccias, but they formed by mass wasting of fault scarps as evident from surface morphology and intercalation of the breccias with mudstones.

The difficulties in distinguishing tectonic from sedimentary breccias are evident from comparing the characteristics of sedimentary breccias that might form at mid-ocean ridges (Table 1) with those formed by faulting (Table 2), especially when taking into account the fact that the contacts of breccias with intact rocks are generally not preserved in drill core. The problems with interpreting the origin of breccias in drill core are illustrated by two breccias from Hole 896A shown in Figures 8 and 9. The breccia in Figure 8 comes from a breccia horizon between 431.5 and $433 \mathrm{~m}$ below seafloor (mbsf). The entire $1.5 \mathrm{~m}$ of core is breccia, representing $38 \%$ recovery for the $4-\mathrm{m}$ interval drilled. The breccia contains a variety of clasts, including glass and basalts having a wide variety of color and texture. Some of the basalt clasts contain veins that are truncated at the edge of the clast (Alt, Kinoshita, Stokking, et al., 1993). Clasts are angular to subrounded. In thin section, it is evident that the matrix consists of sand-size clasts, generally with sharply defined boundaries, cemented with smectite. There is no evidence of crushing as would be expected from frictional wear. Based on these criteria, this type of breccia was interpreted as forming on the seafloor as talus or possibly as a fissure fill (Alt, Kinoshita, Stokking, et al., 1993). This could just as well be a tectonic breccia, however. One microscopic texture that is consistent with a tectonic origin is that some clast margins show microfracturing such that they appear to grade into the smectite-cemented matrix. If the breccia is tectonic in origin, the lack of cataclasis and clay-size sediment as well as the increase in volume required by the presence of substantial cement filled pores could be the result of dilational faulting. The large variety of rock types as clasts might be the result of mixing of rocks derived from the walls of the fault zone during significant fault displacement. If this breccia were on land, it might be evident that it is tectonic or sedimentary based on the nature of the contact with surrounding rocks (e.g., its dip, sharp vs. gradational contact, presence or absence of slickensides). The contacts of this breccia unit are not preserved in drill core, and more than $65 \%$ of this $4-\mathrm{m}$-thick drilled interval was not recovered.

A second breccia of uncertain sedimentary or tectonic origin is shown in Figure 9A. It contains angular clasts of glass and basalt cemented by smectite and carbonate. It was interpreted by Alt, $\mathrm{Ki}$ noshita, Stokking, et al. (1993) as a hyaloclastite (i.e., formed by shattering of glass as lava was quenched by seawater). A hyaloclastite origin does not readily explain the mixing of basalt and glass, unless it was redeposited after quenching and shattering of the glass. This breccia could just as well be tectonic in origin, again with the disaggregation and pores (now filled with smectite and carbonate cement) produced during dilational faulting. A tectonic origin is perhaps suggested by the presence of smectite-filled fractures in the basalt subparallel to the edge of the breccia.

Figure 9B shows an unusual breccia consisting of very angular fragments suspended in cement consisting of smectite and carbonate. A sedimentary origin of this breccia is unlikely because (1) any transport of the clasts on the seafloor would break the delicate tips evident on some of the clasts and (2) a sedimentary breccia would not have clasts in a cement-supported matrix. An origin by frictional sliding along a fault is also unlikely because of the large pore volume and preservation of delicate tips. Thus an origin beneath the seafloor by either dilational faulting or formation of an extension fracture appears likely. The very large pore space in the sample, resulting in clasts suspended in cement, suggests fragmentation and volume increase occurred synchronously with fluid flow and mineral precipitation.

Many breccias, such as those shown in Figures 8 and 9A, show that the origin of many breccias in DSDP and ODP drill cores is ambiguous, but the possibility of a tectonic rather than sedimentary ori- 
Table 1. Summary of characteristics of nontectonic breccias that may form on mid-ocean ridges.

\begin{tabular}{|c|c|c|c|c|c|}
\hline & Rockfall/debris slide (talus) & Debris flow & Fissure fill ("Neptune dikes") & Hyaloclastite & $\begin{array}{l}\text { Submarine fountaining or } \\
\text { budding from pillows }\end{array}$ \\
\hline $\begin{array}{l}\text { Structural } \\
\text { association: }\end{array}$ & Interbedded with lava flows & $\begin{array}{l}\text { Interbedded with lava flows. } \\
\text { mudstones, and/or pelagics }\end{array}$ & Fills steeply dipping fractures & $\begin{array}{l}\text { Along pillow } \\
\text { margins }\end{array}$ & $\begin{array}{l}\text { Typically occurs at tops of } \\
\text { lava flows }\end{array}$ \\
\hline Textural features: & Angular clasts & Angular clasts & Angular clasts & Very angular clasts & $\begin{array}{l}\text { Irregularly shaped pillows, } \\
\text { glass globules, some } \\
\text { angular glass }\end{array}$ \\
\hline Clast size: & $\begin{array}{l}\text { Very coarse grained (controlled } \\
\text { by jointing in source outcrop) }\end{array}$ & $\begin{array}{l}\text { Mostly very fine grained, but } \\
\text { large clasts may be present }\end{array}$ & $\begin{array}{l}\text { Clast size can vary greatly, } \\
\text { ranging up to boulder size }\end{array}$ & Generally $<10 \mathrm{~cm}$ & $\sim 0.2 \mathrm{~mm}$ to $1 \mathrm{~m}$ \\
\hline $\begin{array}{l}\text { Internal clast } \\
\text { deformation: }\end{array}$ & $\begin{array}{l}\text { None unless already present in } \\
\text { source outcrop }\end{array}$ & $\begin{array}{l}\text { None unless already present in } \\
\text { source outcrop }\end{array}$ & None & None & None \\
\hline Sorting: & Moderately to well sorted & Poorly sorted (matrix supported) & Moderate to well sorted & Moderately sorted & Poorly sorted \\
\hline Clast composition: & $\begin{array}{l}\text { Unimodal on small scarps; } \\
\text { bimodal or polymict on large } \\
\text { scarps }\end{array}$ & Polymict & $\begin{array}{l}\text { Unimodal to polymict (from } \\
\text { walls of fissure) }\end{array}$ & Glass & $\begin{array}{l}\text { Glass in matrix, basalt in } \\
\text { pillows with glassy rinds }\end{array}$ \\
\hline $\begin{array}{l}\text { Matrix } \\
\text { composition: }\end{array}$ & Hydrothermal cement & $\begin{array}{l}\text { Very angular basalt and mineral } \\
\text { clasts }\end{array}$ & $\begin{array}{l}\text { Pelagic sediment and/or } \\
\text { hydrothermal cement }\end{array}$ & $\begin{array}{l}\text { Hydrothermal } \\
\text { cement }\end{array}$ & Glass globules and fragments \\
\hline Bedding: & $\begin{array}{l}\text { May be crudely bedded; } \\
\text { deposits dip }-30^{\circ}-40^{\circ}\end{array}$ & None to crudely bedded & $\begin{array}{l}\text { Local lamination and/or very thin } \\
\text { discontinuous beds; geopetal } \\
\text { structures possible }\end{array}$ & $\begin{array}{l}\text { None unless } \\
\text { resedimented }\end{array}$ & None \\
\hline Reference: & $\begin{array}{l}\text { Young (1972), Furnes and } \\
\text { Fridleifsson, (1979), Barany } \\
\text { and Karson (1989) }\end{array}$ & Barany and Karson (1989) & Smart et al. (1987) & $\begin{array}{l}\text { Fisher and } \\
\text { Schminke (1984) }\end{array}$ & $\begin{array}{l}\text { Carlisle (1963), Harper } \\
\text { (1984), Fisher and } \\
\text { Schminke (1984) }\end{array}$ \\
\hline
\end{tabular}

Table 2. Summary of characteristics of fault breccias.

\begin{tabular}{|c|c|c|c|c|}
\hline & Attrition & Distributed crushing & "Implosion"a & Disaggregation \\
\hline Structural association: & $\begin{array}{l}\text { Planar shear zones; major } \\
\text { shear displacement }\end{array}$ & $\begin{array}{l}\text { Vicinity of antidilational jogs }{ }^{\mathrm{b}} \text {; minor } \\
\text { shear displacement }\end{array}$ & $\begin{array}{l}\text { Dilational jogs }{ }^{\text {b } ; ~ s u b s i d i a r y ~} \\
\text { extension fractures }\end{array}$ & Dilational faults ${ }^{\mathrm{c}}$; longitudinal splitting ${ }^{\mathrm{d}}$ \\
\hline Textural features: & Extensively rolled clasts & Widespread pervasive microfracturing & $\begin{array}{l}\text { Jigsaw-puzzle textures; } \\
\text { very angular clasts }\end{array}$ & $\begin{array}{l}\text { Jigsaw-puzzle to random fabric; very angular } \\
\text { clasts }\end{array}$ \\
\hline Internal clast deformation: & High & Moderate to high & Low & Low \\
\hline Sorting: & Poor to moderate & Poor & Often well sorted & Well to moderate \\
\hline Clast composition: & Often bimodal or polymict & Often unimodal & Often unimodal & Often bimodal to polymict \\
\hline Matrix composition: & Similar to clasts & Similar to clasts (minor hydrothermal) & Often hydrothermal & Hydrothermal, often with many sand-size clasts \\
\hline Reference: & Sibson (1986) & Sibson (1986) & Sibson (1986) & This study \\
\hline
\end{tabular}

a The rock increases in volume, so the rock is actually undergoing explosion.

${ }^{\mathrm{b}}$ See Figure 15.

${ }^{\mathrm{c}}$ See Figure 3B.

${ }^{\mathrm{d}}$ See Figure 16

gin needs to be carefully considered for all breccias. We are particularly concerned with the recognition of tectonic breccias which form beneath the seafloor as a result of faulting, dilational faulting, or fissuring. We will now focus on breccias and associated vein networks that we think show features that strongly suggest such an origin.

\section{Jigsaw-puzzle Breccias and Vein Networks}

The most common type of breccias of probable tectonic origin in Hole $896 \mathrm{~A}$ are jigsaw-puzzle breccias, where clasts have moved only slightly and can be pieced back together (Figs. 10,11A). In one sample a chilled dike margin is brecciated (Fig. 10A) and is very similar to a brecciated dike margin sampled in the sheeted dike complex of Hole 504B (Dick, Erzinger, Stokking, et al., 1992). Microscopic jigsaw-puzzle breccias occur within many veins (Figs. 11A, 12). Clasts are typically angular, but some are subangular to subrounded (Fig. 11A). The occurrence of subrounded clasts in jigsaw-puzzle breccias, where there has clearly been very little displacement of clasts, indicates that abrasion is not always necessary to produce subrounded clasts.

Fragment size in the jigsaw-puzzle breccias is highly variable, but in thin section there appears to be no clay-size material derived from the rock. Instead, fragments, which may be as small as sand or coarse silt, are cemented by dark-green smectite of hydrothermal origin (Alt, Kinoshita, Stokking, et al., 1993). In some samples, however, plagioclase is replaced by smectite along the margins of clasts, thus obscur- ing boundaries between dark-green smectite cement and host rock. Some of the largest voids are lined by dark-green smectite which were later filled by light-green smectite and blocky carbonate (Fig. 10B). The precipitation of light-green smectite and blocky carbonate after precipitation of dark-green smectite is characteristic of rocks recovered from Hole 896A (Alt, Kinoshita, Stokking, et al., 1993). The spherulitic (vermicular) texture of the light-green smectite, blocky (sometimes euhedral) texture of the carbonate, and the void geometry (matching walls) indicate that they are in fact voids filled by minerals precipitated out of solution (as opposed to replacement features).

The texture of jigsaw-puzzle breccias clearly indicates an increase in volume by opening of spaces between clasts. The volume increase is highly variable at many scales, even within a single sample (Figs. $10,11 \mathrm{~A}$ ), but ranges from a few percent to more than $25 \%$ (e.g., Fig. 11A). In Hole 896A, jigsaw-puzzle breccias are intimately associated with vein networks filled with dark-green smectite (Figs. 10B, 12, 13). Vein networks in individual samples commonly have a preferred orientation (Fig. 13), but the veins are anastomosing, branching, and sometimes discontinuous. Microscopic jigsaw-puzzle breccias occur within many of the individual veins (Fig. 12), and some veins essentially consist of microbreccia (Fig. 11A). Measurements of veins in some vein networks show that they have a geometry which indicates extension in several different directions (Fig. 11B; Dilek et al., chapter 18 , this volume). As with the jigsaw-puzzle breccias, veins were filled with dark-green smectite followed by precipitation of lightgreen vermicular smectite \pm carbonate in voids (Fig. 11B). Some of these vein networks, such as the one shown in Figure 13, were previ- 

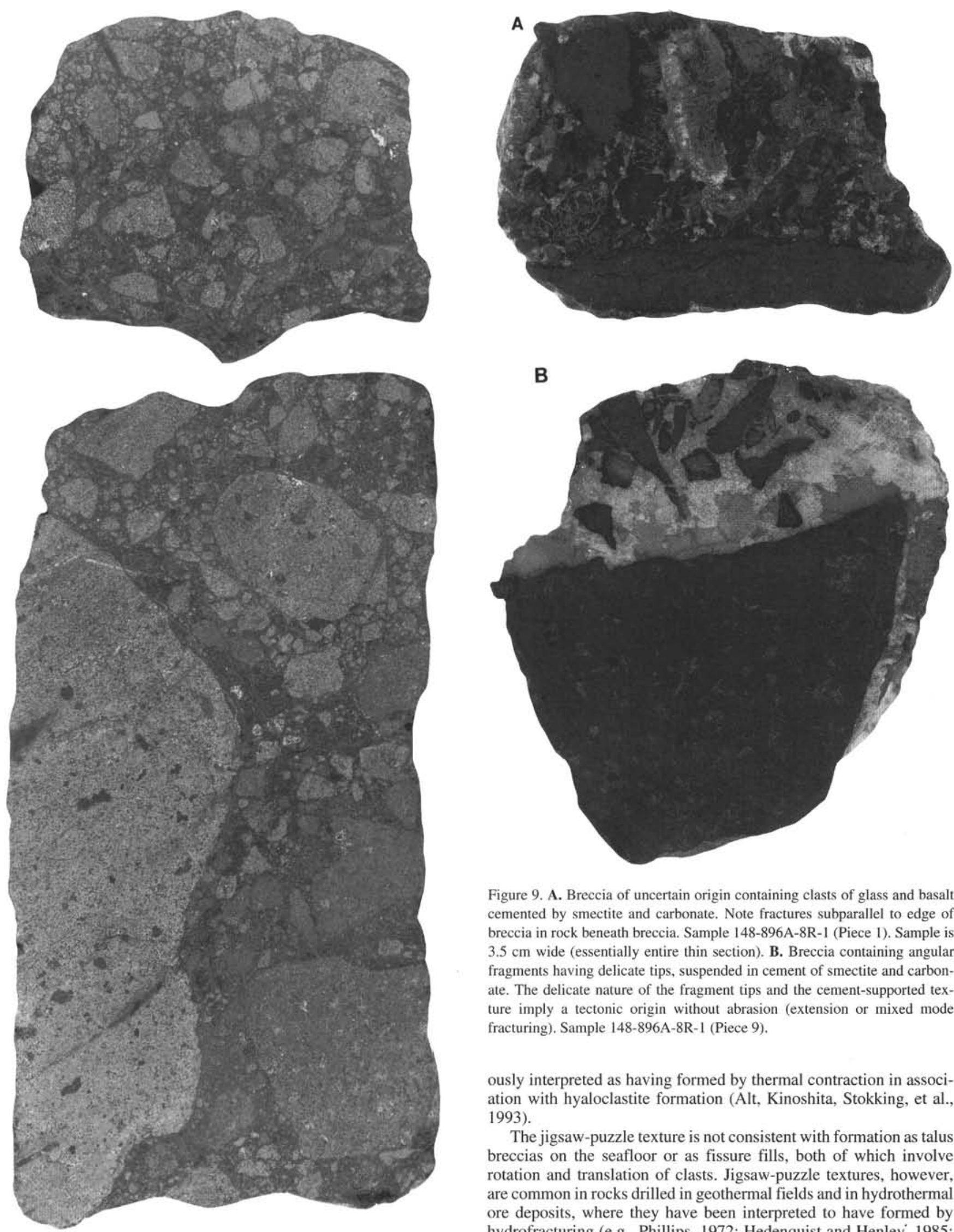

Figure 9. A. Breccia of uncertain origin containing clasts of glass and basalt cemented by smectite and carbonate. Note fractures subparallel to edge of breccia in rock beneath breccia. Sample 148-896A-8R-1 (Piece 1). Sample is $3.5 \mathrm{~cm}$ wide (essentially entire thin section). B. Breccia containing angular fragments having delicate tips, suspended in cement of smectite and carbonate. The delicate nature of the fragment tips and the cement-supported texture imply a tectonic origin without abrasion (extension or mixed mode fracturing). Sample 148-896A-8R-1 (Piece 9).

ously interpreted as having formed by thermal contraction in association with hyaloclastite formation (Alt, Kinoshita, Stokking, et al., 1993).

The jigsaw-puzzle texture is not consistent with formation as talus breccias on the seafloor or as fissure fills, both of which involve rotation and translation of clasts. Jigsaw-puzzle textures, however, are common in rocks drilled in geothermal fields and in hydrothermal ore deposits, where they have been interpreted to have formed by hydrofracturing (e.g., Phillips, 1972; Hedenquist and Henley, 1985; Sibson, 1987; Gianelli and Bertini, 1993). Jigsaw-puzzle breccias filled with hydrothermal minerals are also common along smallnature of clasts which consist of basalt and glass. Note slight rounding of some clasts. Sample 148-896A-27R-2 (Pieces 5A and 5B). 

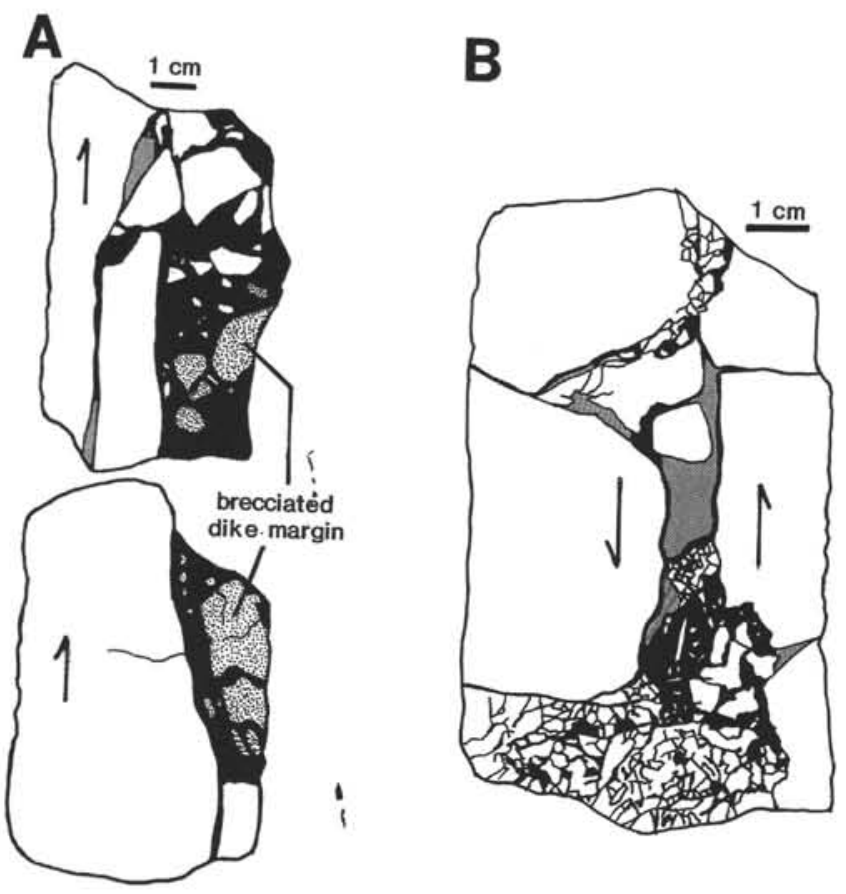

Figure 10. Breccias and vein networks. Black is microbreccia cemented by dark-green smectite; light gray are voids filled with vermicular smectite and carbonate. A. Brecciated chilled dike margin. Sense of offset based on clast geometry and shape of triangular-shaped filled void (gray) near top of sample. Sample 148-896A-21R-2 (Pieces 9A and 9B). B. Vertical breccia zone grading downward into vein network. Sense of offset is based on geometry of filled void (gray). Sample 148-896A-23R-1 (Piece 15).

offset oceanic faults in the basal sheeted dike complex of the Josephine ophiolite (Alexander et al., 1993). In Hole 896A, the steep dips of a limited number of measured breccia margins and microbrecciafilled veins (Fig. 14) also suggests a tectonic rather than sedimentary origin of the jigsaw-puzzle breccias. Although few breccia margins were measured during the cruise, reexamination of photographs of the Hole 896A core in Alt, Kinoshita, Stokking, et al. (1993) shows a predominance of moderate to steeply dipping margins of breccias. In addition, on FMS images of intervals in Hole 896A where substantial breccias were recovered in core, there are numerous steeply dipping subplanar contacts between relatively uniform bright areas (probably basalt) and mottled dark areas (probably breccia as seawater- or smectite-filled pores will show dark due to low resistivity; P. Pezard, pers. comm., 1994).

The strain recorded by these breccias is an overall increase in volume, with the pores filled by hydrothermal minerals (dark-green smectite followed by light-green smectite \pm carbonate in voids). The geometry of many of the breccias and vein networks, however, also shows that shear displacements are common. This is evident in Figure $11 \mathrm{~A}$ by the rectangular void (pull-apart) filled by vermicular smectite and carbonate. In Figure $12 \mathrm{~A}$, the geometry of the vein network, which terminates at its base against a smectite vein, indicates that the upper left block has moved to the left. Shear displacement is evident in the vein shown in Figure 12B by a trail of clasts derived from a plagioclase phenocryst and in the vein in Figure $12 \mathrm{C}$ by an offset phenocryst.

Although many of the jigsaw-puzzle breccias and vein networks show evidence for shear displacement, they are clearly very different from breccias formed by frictional sliding (Table 2). Sibson (1985, 1986, 1987) discusses field and earthquake observations that suggest jigsaw-puzzle breccias can form in dilational fault jogs (Fig. 15). In his model, brecciation results from "implosion" caused by a rapid opening of a dilational fault jog during an earthquake (note that this
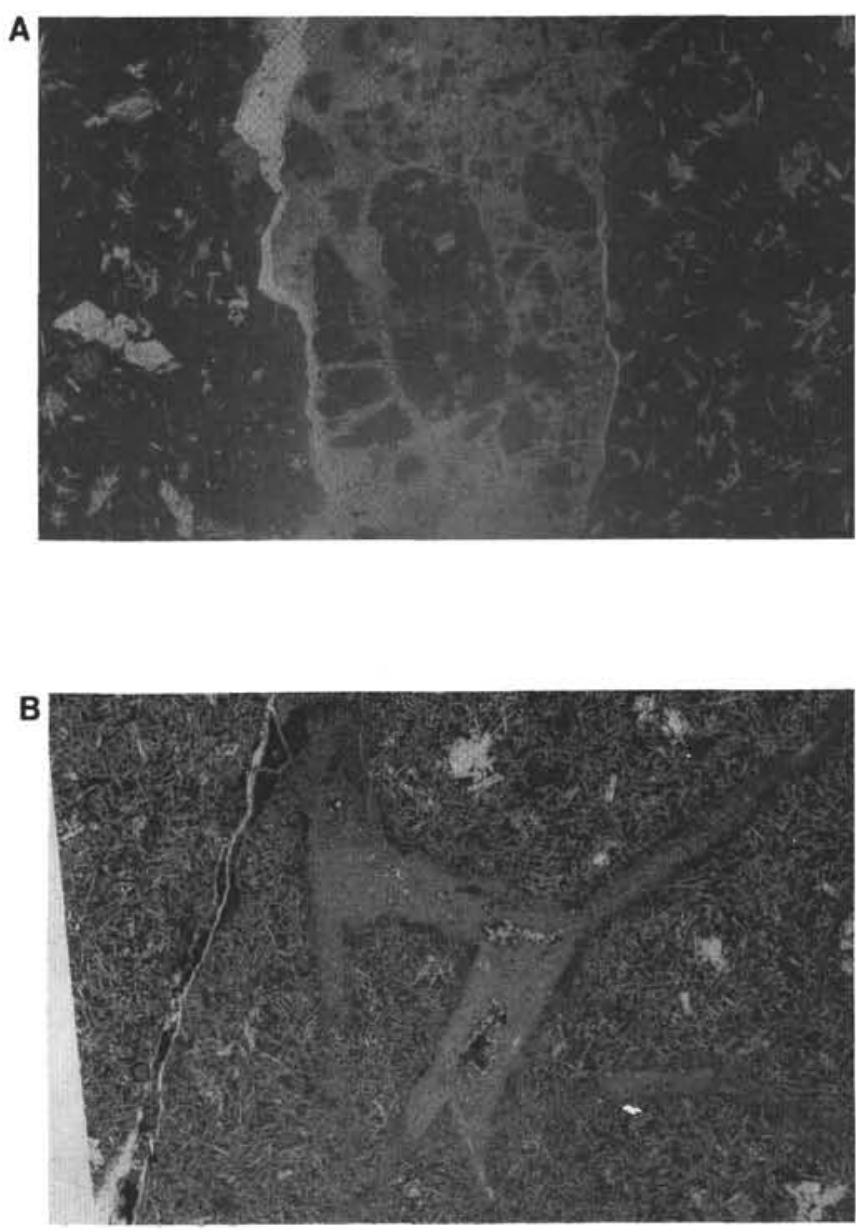

Figure 11. A. Photomicrograph showing vein of breccia within basalt. Note jigsaw-puzzle defined by larger clasts. Width of view is $3.5 \mathrm{~cm}$. Sample 148 896A-30R-1 (Piece 15). B. Photomicrograph of intersecting veins with voids filled by light-green vermicular smectite (veins are oriented at a high angle to plane of thin section). Note that filled voids are lined with early dark-green smectite. Geometry of void in 3-D indicates extension in several directions, probably simultaneously. Width of field is $2.5 \mathrm{~cm}$. Sample 148-896A-2IR-1 (Piece 17).

is actually an explosion in the sense used by seismologists because there is a volume increase). Because of the high rate of opening, fluid pressures will be lower in the void creating a suction force and, if the difference in fluid pressure $(\Delta \mathrm{P})$ is greater than the tensile strength of the rock, "implosion" will occur. Because of the thick water column above mid-ocean ridges, the potential $\Delta \mathrm{P}$ is $\sim 25 \mathrm{MPa}$ (corresponding to $2500 \mathrm{~m}$ water depth) for the limiting case of an instantaneous opening, which far exceeds the static tensile strength of mafic rocks as discussed above. It should be noted, however, that the tensile strengths of rocks under impulsive loading (dynamic fracturing) are considerably higher than for static loading, with dynamic tensile strengths for crystalline rocks typically on the order of $\sim 100 \mathrm{MPa}$ (Grady and Kipp, 1987). Such high static and dynamic tensile strengths are for the formation of new fractures; the upper ocean crust will generally have preexisting fractures (e.g., cooling joints) that, unless heavily cemented, will have a much lower (possibly negligible) tensile strength. "Implosion" can also occur by rapid slip on dilational faults because of the associated volume increase and should also be possible at the tips of fractures when they propagate rapidly. Dynamic fracturing, such as that which occurs during and explosion or implosion, can be an important process in rock fragmentation because fractures of many orientations are formed, in contrast to a single 
Figure 12. Sketches from thin section of jigsaw-puzzle-textured microbreccias associated with dark-green smectite veins. A. Microbreccia terminating in a smectite vein. The increase in volume of the brecciated zone requires that the upper left block moved toward the left as shown by arrow. Sample 148-896A-18R-1 (Piece 1). B. Microbreccia in vein. Displacement along vein indicated by fragmented phenocryst on left (black). Sample 148-896A-25R-1 (Piece 12). C. Vein containing microbreccia. Displacement indicated by offset plagioclase phenocryst. Sample 148-896A18R-2 (Piece 9).
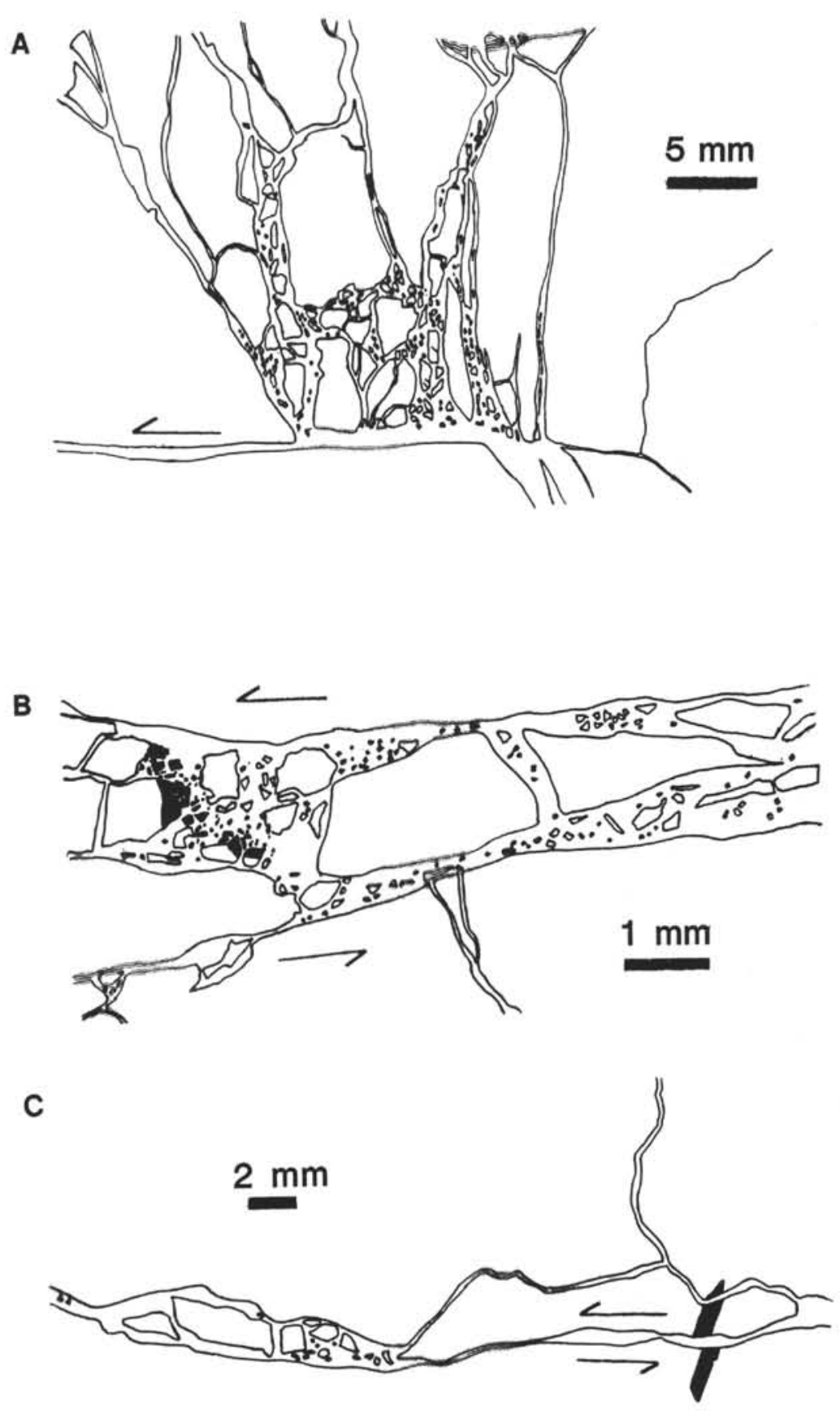

orientation (extension fractures oriented normal to $\sigma_{3}$ ) under quasistatic loading conditions (Grady and Kipp, 1987).

"Implosion" may have contributed to the formation of jigsawpuzzle breccias and associated vein networks, but fragmentation may be primarily the result of formation of anastomosing extension fractures under conditions of very low effective stresses. In laboratory experiments, compressive loading of rock specimens under conditions of no confining pressure (uniaxial compression) often results in longitudinal (axial) splitting (Fig. 16; Heard, 1960; Brace, 1964; Twiss and Moores, 1992). Multiple anastomosing and branching extension fractures are formed, and much of the sample may be fragmented into small pieces (Fig. 16). These experimental conditions are similar to the shallow ocean crust where vertical effective stress $\left(\sigma_{1}{ }^{\prime}\right)$ is low and effective confining pressure $\left(\sigma_{3}{ }^{\prime}\right.$ and $\left.\sigma_{2}{ }^{\prime}\right)$ is $\leq 0$ due to high hydrostatic pore-fluid pressures. Longitudinal splitting is very similar in morphology to the anastomosing vein networks associated with jigsaw-puzzle breccias in the drill core of Hole 896A. The anastomosing and branching network of fractures results in fragmentation of the rock within the fracture network, and as the rock continues to dilate these fragments may move apart and rotate to form jigsaw-puzzle breccias. The large volume increase evident in the jigsaw-puzzle breccias and vein networks is consistent with this origin in that a tensional confining pressure will allow expansion in the $\sigma_{3}{ }^{\prime}$ and $\sigma_{2}{ }^{\prime}$ plane (or in the direction of $\sigma_{3}{ }^{\prime}$ if $\sigma_{2}{ }^{\prime}$ is positive).

In light of the above discussion, the jigsaw-puzzle breccias and vein networks are interpreted to have formed within extension fracture networks and dilational faults (Fig. 3A, B), but at very low effective stresses $\left(\sigma_{3}{ }^{\prime}<0\right)$ such that anastomosing and branching fractures 


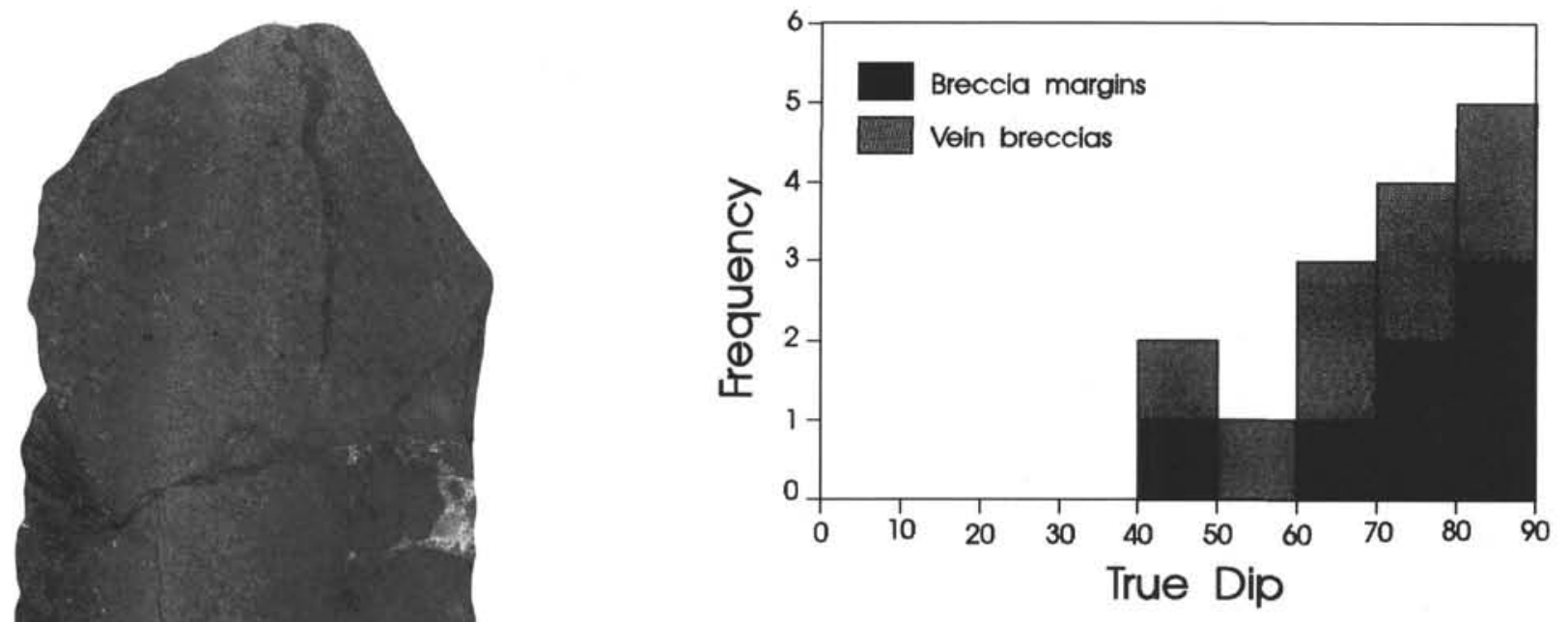

Figure 14. Histogram showing dips of breccia margins and vein breccias (veins containing basalt fragments such as that shown in Fig. 11A) measured in drill core.

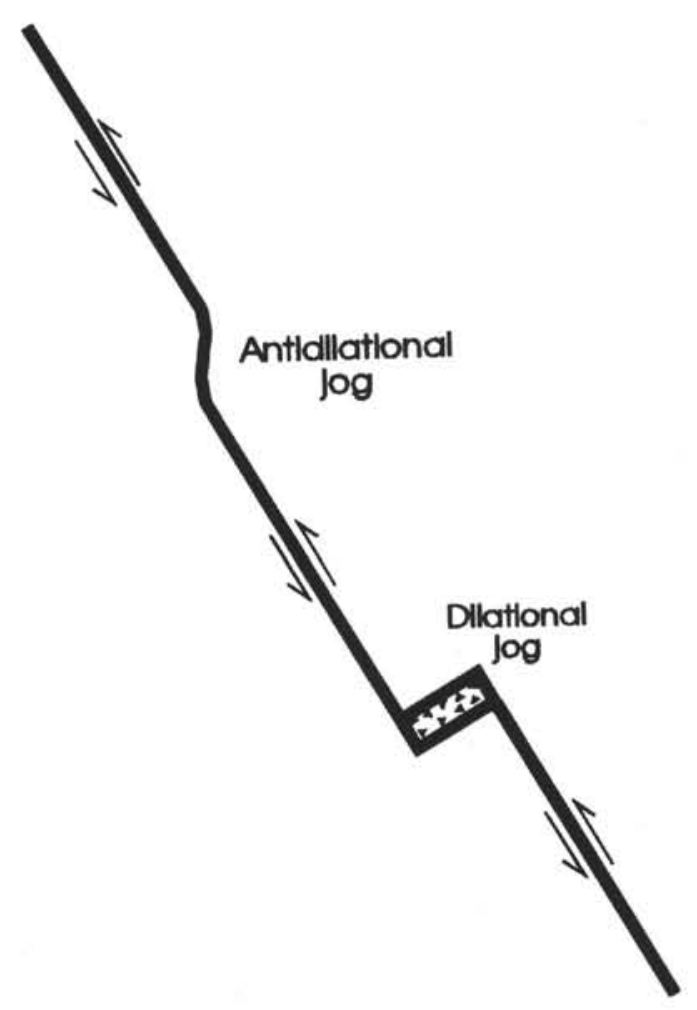

Figure 15. Illustration of dilational and antidilational jogs on a fault. Dilational jogs are a potential site for jigsaw-textured breccias to form by "implosion" (Sibson, 1986; this is actually an explosion in the sense that there is a volume increase of the rock).

are formed. Even though shear displacements may occur, under these conditions there will be little or no internal deformation nor rounding of clasts in resulting breccias. A summary of the characteristics of breccias formed under these conditions is given in the far right column of Table 2. It is interesting to note that jigsaw-puzzle breccias grade into breccias having random fabrics (Fig. 10). Thus, it is possi-

Figure 13. Vein network filled with dark-green smectite along edge of ble that other types of breccias such as those in Figures 8 and 9 could form by the same mechanism. 


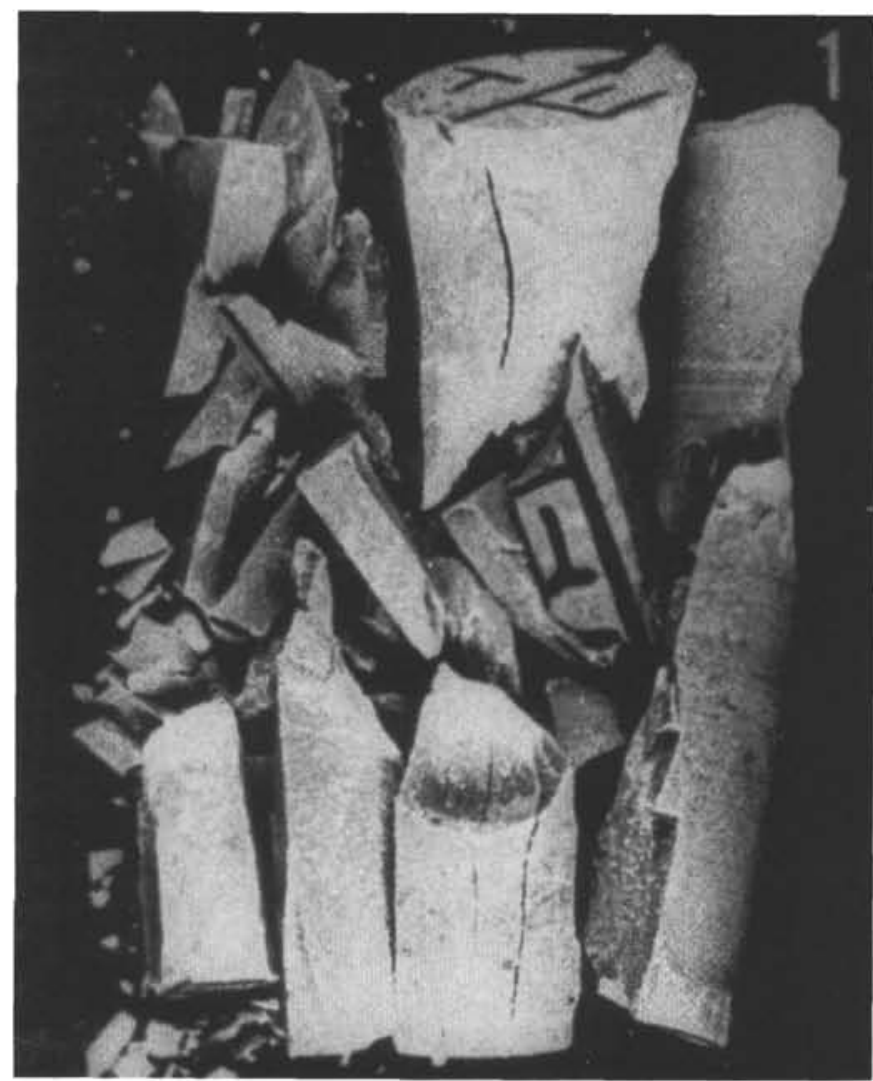

Figure 16. Longitudinal splitting of sample deformed under uniaxial compression ( 1 atmosphere confining pressure) from Heard (1960). Fragmentation is similar to that observed in jigsaw-puzzle breccias and associated vein networks in Hole 896A.

\section{CRACK-SEAL VEINS}

Crack-seal veins have been interpreted as forming from repeated cycles of hydrofracturing followed by mineral precipitation and sealing of the crack (Ramsay, 1980; Etheridge et al., 1984). Mineral precipitation resulting from individual crack-seal cycles can be often be inferred from bands of fluid inclusions, each band generally being only a few tens of microns thick and each crack-seal vein commonly consisting of hundreds of such bands. Fibrous mineral growths are characteristic of crack-seal veins, and the fibers are thought to track the opening direction of the vein. The fibers may be crystallographically oriented (e.g., the basal plane of phyllosilicates typically forms parallel to the fiber axis), but other minerals such as quartz and calcite generally show no correlation of their c crystallographic axes with the long axis of the fiber. These fibers result from incremental additions of a thin overgrowth on mineral faces exposed during the cracking, so that fiber growth is analogous to making columns of coins on a desktop by repeatedly stacking one coin on top of each column. These fibers are perhaps better called "structural fibers" to distinguish them from crystals of prismatic habit formed by growth into free space.

The most common minerals in crack-seal veins are quartz and/or calcite, and in many cases occur together as fibers in crack-seal veins (e.g., Ramsay, 1980). Supersaturation of solute phases caused by the pressure drop during crack propagation, discussed above, has been proposed as the mechanism to cause mineral precipitation resulting in sealing of the crack (Etheridge et al., 1984). This explanation is attractive for minerals such as quartz, but calcite (and aragonite) is more soluble as fluid pressure increases (Bruton and Helgeson,

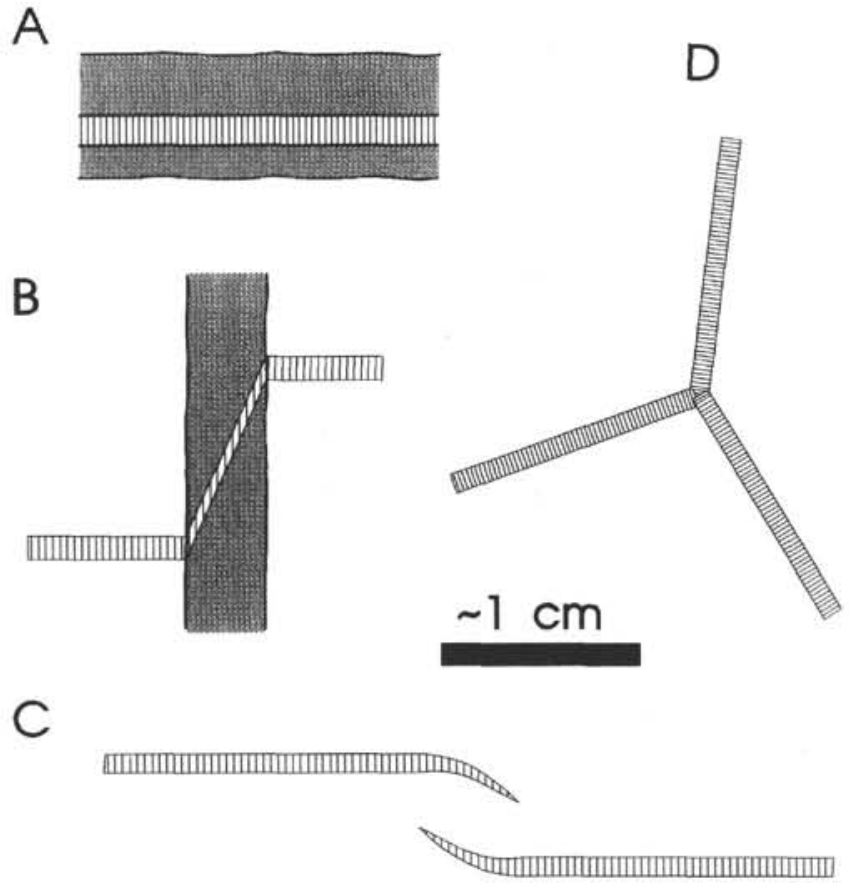

Figure 17. Summary of characteristics of fibrous (crack-seal) veins observed in Hole $896 \mathrm{~A}$. A. Reopening of nonfibrous vein. B. Change from pure extension (Mode I) to oblique extension (mixed mode fracture) as a fibrous vein crosses a nonfibrous vein. Notice fiber orientation remains constant. C. Curved vein tips resulting from overlap of propagating fractures. D. Triple junction of fibrous veins, implying simultaneous extension in three different directions. In hand specimen it is evident that fibers in all three veins are normal to vein walls.

1982). This suggests that the sudden decrease in fluid pressure within the fracture is not the only factor in causing mineral precipitation.

The fibrous veins of inferred crack-seal origin in Hole 896A consist of smectite fibers or smectite + carbonate, with the smectite fibers invariably occurring along the vein walls as well as in vein tips. Some important characteristics of fibrous (crack-seal) veins in Hole 896A are shown in Figure 17. As shown in Figures 17A and 17B, they almost always cut nonfibrous veins consisting of vermicular smectite \pm carbonate, but a very few examples were observed where thin nonfibrous veins cut fibrous veins. Some of the fibrous veins involve reopening of nonfibrous veins (Fig. 17A), whereas others cut across the nonfibrous veins (Fig. 17B). The fibers are generally normal to the walls of the veins as evident in hand specimen and thin section, and offset phenocrysts in thin section suggest they are indeed purely extensional (i.e., mode I fractures). In some veins deeper in the hole (>334 mbsf), however, fibers are oriented obliquely to the walls, implying mixed mode fracturing, or parallel to the walls implying faulting (mode II fractures; Dilek et al., chapter 18, this volume). Figure $17 \mathrm{~B}$ shows an example where fibers have a consistent orientation but the vein orientation varies; the fibers are normal to the vein walls except where the vein crosses a nonfibrous vein, indicating variation from pure extension to dilational faulting. En échelon fibrous veins with curving overlapping tips are common (Fig. 17C). The characteristics of the fibrous veins show that although some formed by reopening of preexisting veins (Fig. 17A) or fractures, many formed as new fractures as evident from crosscutting relationships and the presence of en échelon veins with overlapping tips (Fig. 17C). The appearance of minor faults having fibers parallel to the fault surface observed at depths $\geq 334$ mbsf (Dilek et al., chapter 18, this volume) may mark a transition from extension fracturing to shear failure with depth. 
An enigmatic feature of the fibrous veins in Hole 896A is that they are highly variable in orientation, even within a single core piece, implying extension in several different directions. If the fibers in fact track the incremental strain history (Ramsay, 1980), then the presence of triple junctions of fibrous veins (Fig. 17D) implies that extension was occurring in three different directions at the same time. The fibers from such veins sets within a single core piece, however, sometimes show extension directions mostly lying within a single, generally steeply dipping plane, but the strike of this plane is variable (Dilek et al., chapter 18, this volume). The extension directions inferred from both fibrous and nonfibrous veins oriented paleomagnetically show no strong preferred orientation in azimuth and shallow dips are common (Dilek et al., chapter 18, this volume), although moderate to steep dips are more abundant, especially after allowing for bias due to sampling by a vertical borehole. Because extension fractures in rock deformation experiments form normal to the least principal stress $\left(\sigma_{3}\right)$, it is surprising that the fibrous veins are not primarily vertical and parallel to the ridge axis. For example, in regional metamorphic rocks, fibrous extension veins of crack-seal origin are generally uniform in orientation and oriented normal to the regional extension direction (Etheridge et al., 1984). The few small faults having fibrous slickensides that occur below $334 \mathrm{mbsf}$ also show highly variable orientations, and vary from normal, reverse, to oblique (Dilek et al., chapter 18, this volume).

The large variation in extension directions for fibrous veins and mode of faulting in Hole 896A may be partly due to spatial and/or temporal rotations of the local stress field caused by heterogeneities in the rock (e.g., pillows, open cooling joints). Agar (1990, 1991), for example, noted that changing orientations of successive generations of veins in drill core from Hole 504B indicates rotation of the local stress field (specifically $\sigma_{3}$ ) with time by amounts ranging form $30^{\circ}$ to $120^{\circ}$. This explanation, however, does not explain simultaneous extension in several directions as implied by triple junctions (Fig. 17D). The strain recorded by the fibrous veins (including the less common oblique and fracture-parallel fibers) appears to be similar to that recorded by nonfibrous veins; that is, primarily an overall volume increase, accompanied at least locally by some shear displacement (oblique and fracture parallel fibers at depths $>334 \mathrm{mbsf}$ ). This strain could be viewed as an incipient type of brecciation because individual blocks must move apart to account for simultaneous extension in several directions. Extension in many directions may be the result of $\sigma_{2}{ }^{\prime}$ as well as $\sigma_{3}{ }^{\prime}$ being tensional, which is likely in the uppermost crust where the ratio of pore-fluid pressures to the vertical load $\left(\sigma_{1}\right)$ is very high. In this case, the rock could expand in any direction within the plane of $\sigma_{2}{ }^{\prime}$ and $\sigma_{3}{ }^{\prime}$. This is consistent with the orientations of fibrous veins from individual pieces of the drill core whose poles lie within a plane, implying extension in many directions within a single plane (Dilek et al., chapter 18, this volume). If this is the case, the variable strike of these planes from piece to piece implies a highly variable regional stress field, and the subvertical dip of many of these planes further implies that $\sigma_{1}{ }^{\prime}$ can locally be horizontal.

\section{DISCUSSION}

The strain recorded by crack-seal veins, vein networks, and jigsaw-puzzle breccias in Hole $896 \mathrm{~A}$ is predominantly a volume increase. The orientations of these veins indicate extension in many different directions, including vertical (Dilek et al., chapter 18, this volume). Mixed mode fracturing, where the walls of the fault move apart as well as laterally, is evident in some jigsaw-puzzle breccias, vein networks, and veins containing oblique fibers. Small faults having fibers oriented subparallel to the fault are also present deeper in the hole.

The anastomosing vein networks and jigsaw-puzzle breccias in Hole 896A most likely formed by "longitudinal splitting" observed in rock deformation experiments where vertical effective stress $\left(\sigma_{1}{ }^{\prime}\right)$ is low and effective confining pressure $\left(\sigma_{3}{ }^{\prime}\right.$ and $\left.\sigma_{2}{ }^{\prime}\right)$ is $\leq 0$ (i.e., tensional). Such stress conditions should exist in the upper ocean crust due to high hydrostatic pressures resulting from the thick overlying water column (Fig. 6). It is very likely that fluid pressures in the upper ocean crust at mid-ocean ridges will be hydrostatic because of the high permeability and porosity resulting from abundant fractures (both cooling and tectonic fractures) and interpillow voids. High permeabilities and porosities have been measured in the $6 \mathrm{Ma}$ extrusive sequence at Hole 504B (Anderson and Zoback, 1982) and were undoubtedly higher when the crust was at the ridge crest as cracks are progressively closed with time by mineral precipitation. Much has been made of the observation that Hole 504B is underpressured, but the fluid pressures are only $3 \%$ below hydrostatic (Anderson and Zoback, 1982). Thus, conditions are favorable for hydrofracturing at this site, even though the basement is sealed by a thick sequence of overlying sediments.

Under conditions of high pore-fluid pressures, faulting is likely to be by mixed mode fracturing (Fig. 3B). Because of the component of extension across the fault, fault rocks produced during dilational faulting should have little or no frictional wear. As a result, fault gouge and attrition breccias (Table 2) are unlikely to form in the uppermost ocean crust. Instead, fault rocks may consist of breccias formed by disaggregation during volume increase (i.e., jigsaw-puzzle breccias and breccias containing appreciable pore space, the latter of which are texturally very similar to breccias formed by sedimentary processes; Tables 1,2). Many of the breccias recovered from Hole 896A show evidence for dilational faulting (Figs. 10, 12; i.e., displacement along planar zones associated with volume increase). "Implosion" by rapid opening of voids along dilational fault jogs (Fig. 15 ) is another mechanism which can produce jigsaw-puzzle breccias (Sibson, 1986). Jigsaw-puzzle breccias cemented by hydrothermal minerals are commonly associated with oceanic faults in ophiolites (Alexander and Harper, 1992; Alexander et al., 1993; Agar, 1994), but also have been documented in dilational jogs along faults in the Josephine ophiolite (Alexander and Harper, 1992). As noted above, jigsaw-puzzle textures are also common in hydrothermal ore deposits and modern geothermal fields.

The sedimentary vs. tectonic origin of breccias (other than those having jigsaw-puzzle textures) is generally ambiguous in drill core, largely because the boundaries of the breccias are often not recovered. Of course, breccias may form by a combination of tectonic and sedimentary processes (e.g., talus accumulation at the base of a fault scarp or filling of a fissure with rubble). Thus, it is uncertain whether or not relatively thick breccia intervals, such as the $>1.5-\mathrm{m}$ interval at 435 mbsf (Fig. 8), represent fault rocks formed in situ or as sedimentary accumulations. A tectonic origin for many such breccias, however, is suggested by the steep dips of those breccia margins sampled in the drill core (Fig. 14), abundant steep boundaries of probable breccia zones evident in the FMS images (mottled zones), and the gradation from jigsaw-puzzle texture to random fabrics evident in some samples. Consideration should be given, therefore, to the possibility that such breccias of uncertain origin that occur below 360 mbsf are related to faulting, either as tectonic breccias formed in fault zones in situ or as talus breccias formed at the foot of fault scarps. The abrupt change in magnetic properties at 360 mbsf, including a steepening of magnetic inclination suggestive of tilting, which coincides with a petrologic boundary (Alt, Kinoshita, Stokking, et al., 1993), may be due to large-scale faulting. Alternatively, these changes may be the result of a protracted period of little magmatism and greater tectonic extension, in which case the crust below $\sim 360 \mathrm{~m}$ may have been tilted and substantial sedimentary breccias accumulated before the recurrence of volcanism.

With few exceptions, crosscutting relationships indicate the jigsaw-puzzle breccias and vein networks associated with precipitation of dark-green smectite were followed by infilling of voids with vermicular smectite and carbonate, which was in turn followed by fi- 
brous veins. Fibrous veins have features characteristic of veins thought to have formed by the crack-seal mechanism (Ramsay, 1980), involving repeated cycles of hydrofracturing followed by sealing due to mineral precipitation. The overall strain represented by the crack-seal veins appears to be similar to that of the jigsaw-puzzle breccias and vein networks, but the strain increments are different. In crack-seal veins, each reopening of a fracture is immediately followed by sealing, whereas formation of jigsaw-puzzle breccias and vein networks resulted in many open voids which were subsequently filled by vermicular smectite and carbonate. The crosscutting relationships suggest that the crack-seal mechanism occurred only after these voids were filled, resulting in a structurally more homogeneous rock. The transition to crack-seal mechanism may also be due to deformation occurring progressively off-axis, where overall strains are lower and resulting in narrower cracks that can seal more rapidly. It should be kept in mind, however, that the crack-seal mechanism of Ramsay (1980) is only a model, and fibrous minerals oriented normal to the vein wall have been grown experimentally in open cavities ( $T$. $\mathrm{Li}$ and W. Means, unpubl. data, 1994). There is also a fundamental problem in the argument that the rapid pressure drop during hydrofracturing causes supersaturation of solute species and consequent increment of fiber growth (e.g., Etheridge et al., 1984). Although sudden pressure drops do cause supersaturation of most solute species such as quartz, calcite is more soluble as fluid pressure increases (Bruton and Helgeson, 1982), yet quartz and calcite fibers commonly occur together as fibers in "crack-seal" veins.

The large variability in vein orientation within single core pieces for Hole 896A makes interpretation of the paleostress field difficult. Do these variable vein orientations suggest rotations of the local or regional stress field, or is the orientation of the vein not normal to the least principle stress $\left(\sigma_{3}\right)$ ? For "true" extension fractures formed in homogeneous rock (Fig. 3A), the least principle stress $\left(\sigma_{3}\right)$ is normal to the fracture. In longitudinal (axial) splitting, however, fractures form in other orientations as well (Fig. 16). Thus, longitudinal splitting is one explanation for the highly variable orientations of apparently synchronous veins (e.g., Figs. 11B, 13, 17B). The large variation in vein orientation as well as the presence of both normal and reverse faults in Hole 896A drill core may be due, in part, to spatial and/or temporal rotations of the local stress field caused by heterogeneities in the rock (e.g., voids between pillows, open cooling joints). Agar $(1990,1991)$ interpreted changing orientations of successive generations of veins in drill core from Hole 504B as the result of rotation of the local stress field (specifically $\sigma_{3}$ ) with time by amounts ranging form $30^{\circ}$ to $120^{\circ}$. The strain recorded by the fibrous veins (including the less common oblique and fracture-parallel fibers) appears to be similar to that recorded by nonfibrous veins; that is, primarily an overall volume increase, accompanied at least locally by some shear displacement (oblique and fracture parallel fibers at depths $>334 \mathrm{mbsf}$ ). This strain could be viewed as an incipient type of brecciation because individual blocks must move apart to account for simultaneous extension in several directions. Extension in many directions may be the result of $\sigma_{2}{ }^{\prime}$ as well as $\sigma_{3}{ }^{\prime}$ being tensional, which is likely in the uppermost crust where the ratio of pore-fluid pressures to the vertical load $\left(\sigma_{1}\right)$ is very high (Fig. 6). In this case, the rock could expand in any direction within the plane of $\sigma_{2}{ }^{\prime}$ and $\sigma_{3}{ }^{\prime}$. This is consistent with the orientations of both fibrous and nonfibrous vein arrays from individual pieces of the drill core whose poles lie within a plane, implying extension in many directions within a single plane (Dilek et al., chapter 18, this volume). If this is the case, the variable strike of these planes from piece to piece implies a highly variable regional stress field, and the subvertical dip of many of these planes further implies that $\sigma_{1}{ }^{\prime}$ can locally be horizontal.

The regional stress field at mid-ocean ridges inferred from large earthquakes and one microseismicity study using ocean-bottom seismometers (Toomey et al., 1985) suggest a uniform stress field where $\sigma_{1}$ is vertical and $\sigma_{3}$ is horizontal and normal to ridge. Recent microseismicity studies in Iceland, however, suggest that this stress field is characteristic of periods between tectonic events and before rifting events. During dike injection, it appears from geodetic measurements that the magma in dikes pushes outward and thus increases $\sigma_{3}$ such that it may become $\sigma_{2}$ or even $\sigma_{1}$. "Geothermal earthquakes," recorded over a three-month interval immediately following a major spreading episode in the Krafla segment, show that there was essentially no systematic orientation of the axes of principle stress. The events appeared to occur on randomly oriented fault planes, including normal, reverse, and strike-slip sources. Some of the events in the Krafla segment, as well as in the Reykjanes and Hengill segments, are non-double-couple earthquakes, commonly having an explosive (volume increase) component (Arnott and Foulger, 1994). Possible mechanisms to produce such earthquakes include simultaneous shear faulting on planes of different orientation, tensile cracking with or without pore-fluid pressure drops, dike injection, and simultaneous tensile and shear failure. The types of brittle deformation observed in Hole $896 \mathrm{~A}$ core, which is characterized by an increase in volume, would result in non-double-couple mechanisms with an explosive component (Arnott and Foulger, 1994). A few poorly constrained non-double-couple microseismic events have been recorded to date on mid-ocean ridges (Toomey et al., 1985). Future detailed microseismicity studies using dense OBS arrays may be able to test whether there is a stress cycle at mid-ocean ridges associated with rifting events, and whether the microseismicity is consistent with the structures observed at Hole 896A.

\section{REFERENCES}

Agar, S.M., 1990. Fracture evolution in the upper ocean crust: evidence from DSDP Hole 504B. In Knipe, R.J., and Rutter, E.H. (Eds.), Deformation Mechanisms, Rheology and Tectonics. Geol. Soc. Spec. Publ., London, $54: 41-50$.

1991. Microstructural evolution of a deformation zone in the upper ocean crust: evidence from DSDP Hole 504B. .J. Geodyn., 13: $119-140$.

1994. Rheological evolution of the ocean crust: a microstructural view. J. Geophys. Res., 99:3175-3200.

Alexander, R., and Harper, G.D., 1992. The Josephine ophiolite, an ancient analog for oceanic lithosphere formed at slow/intermediate spreading centers. In Parsons, B., and Browning, P. (Eds.), Ophiolites and Their Modern Ocean Analogues. J. Geol. Soc. London, Spec. Publ., 60:3-38.

Alexander, R., Harper, G.D., and Bowman, J.R., 1993. Oceanic faulting and fault-controlled subseafloor hydrothermal alteration in the sheeted dike complex of the Josephine ophiolite. J. Geophys. Res., 98:9731-9759.

Alt, J.C., Kinoshita, H., Stokking, L.B., et al., 1993. Proc. ODP, Init. Repts., 148: College Station, TX (Ocean Drilling Program).

Anderson, O.L., and Grew, P.C., 1977. Stress corrosion theory of crack propagation with applications to geophysics. Rev. Geophys Space Phys., 15: 77-104.

Anderson, R.N., and Zoback, M.D., 1982. Permeability, underpressures, and convection in the oceanic crust near the Costa Rica rift, eastern equatorial Pacific. J. Geophys. Res., 87:3860-2868.

Arnott, S.K., and Foulger, G.R., 1994. The Krafla spreading segment, Iceland 2. The accretionary stress cycle and nonshear earthquake focal mechanisms. J. Geophys. Res., 99:23827-23842.

Atkinson, B.K., and Meredith, P.G., 1987. The theory of subcritical crack growth with applications to minerals and rocks. In Atkinson, B.K. (Ed.), Fracture Mechanics of Rock: New York (Academic Press), 111-166.

Barany, I., and Karson, J.A., 1989, Basalitc breccias of the Clipperton fracture zone (east Pacific): sedimentation and tectonics in a fast-slipping oceanic transform. Geol. Soc. Am. Bull., 101:304-220.

Becker, K., Sakai, H., Adamson, A.C., et al., 1989. Drilling deep into young oceanic crust, Hole 504B, Costa Rica Rift. Rev. Geophys., 37:79-102.

Bolt, B.A., 1993. Earthquakes: New York (Freeman).

Brace, W.F., 1964. Brittle fracture of rocks. In Judd, W.R. (Ed.), State of Stress in the Earth's Crust. New York (Elsevier), 111-174.

Bruton, C.J., and Helgeson, H.C., 1982. Calculation of the chemical and thermodynamic consequences of differences between fluid and geostatic pressure in hydrothermal systems. Am. J. Sci., 283A:540-588.

Byerlee, J., 1978. Friction of rocks. Pure Appl. Phys., 116:615-626.

Carlisle, D., 1963. Pillow breccias and their aquagene tuffs, Quadra Island, British Columbia. J. Geol., 71:48-71. 
Carlson, R.L., and Herrick, C.N., 1990. Densities and porosities in the oceanic crust and their variations with depth and age. J. Geophys. Res., 95: 9153-9170.

Choukroune, P., 1977. Structural study of basaltic rocks showing brittle deformation (Deep Sea Drilling Project Legs 51, 52, and 53, Sites 417 and 418). In Donnelly, T., Francheteau, J., et al., Init. Repts. DSDP, 5153, Part 2: Washington (U.S. Govt. Printing Office), 1491-1498.

Dick, H.J.B., Erzinger, J., Stokking, L.B., et al., 1992. Proc. ODP, Init. Repts., 140: College Station, TX (Ocean Drilling Program).

Dick, H.J.B., Meyer, P.S., Bloomer, S., Kirby, S., Stakes, D., and Mawer, C., 1991. Lithostratigraphic evolution of an in-situ section of oceanic Layer 3. In Von Herzen, R.P., Robinson, P.T., et al., Proc. ODP, Sci. Results, 118: College Station, TX (Ocean Drilling Program), 439-538.

Donath, F.A., 1961. Experimental study of shear failure in anisotropic rocks. Geol. Soc. Am. Bull., 72:985-990.

Etheridge, M.A., 1983. Differential stress magnitudes during regional deformation and metamorphism: upper bound imposed by tensile fracturing. Geology, 11:331-234.

Etheridge, M.A., Wall, V.J., and Cox, S.F., 1984. High fluid pressures during regional metamorphism and deformation: implications for mass transport and deformation mechanisms. J. Geophys. Res., 89:4344-4358.

Fisher, R.V., and Schmincke, H.-U., 1984. Pyroclastic Rocks. New York (Springer-Verlag).

Furnes, H., and Fridleifsson, B., 1979. Pillow block breccia-occurrences and mode of formation. N. Jb. Geol. Pal. Mh., 3:147-154.

Gianelli, N., and Bertini, G., 1993. Natural hydraulic fracturing in the Larderello geothermal field: evidence from well MV5A. Boll. Soc. Geol. It., 112:507-512

Gillis, K., Mével, C., Allan, J., et al., 1993. Proc. ODP, Init. Repts., 147: College Station, TX (Ocean Drilling Program).

Grady, D.E., and Kipp, M.E., 1987. Dynamic rock fragmentation. In Atkinson, B.K. (Ed.), Fracture Mechanics of Rock: New York (Academic Press), 429-475.

Hancock, P.L., Al-Kadhi, A., Barka., A.A., and Bevan, T.G., 1987. Aspects of analyzing brittle structures. Annales Tectonicae, 1:5-19.

Harper, G.D., 1984. The Josephine ophiolite, northwestern California. Geol. Soc. Am. Bull., 95:1009-1026.

Heard, H.C., 1960. Transition from brittle fracture to ductile flow in Solenhofen Limestone as a function of temperature, confining pressure, and interstitial fluid pressure. In Griggs, D., and Handin, J. (Ed.), Deformation. Geol. Soc. Am. Mem., 79:193-226.

Hedenquist, J.W., and Henley. W.H., 1985. Hydrothermal eruptions in the Waiotapu geothermal system, New Zealand: their origin, associated breccias, and relation to precious metal mineralization. Econ. Geol., 80: $1640-1668$.

Macdonald, K.C., 1983. Crustal processes at spreading centers. Rev. Geophys. Space Phys., 31:1441-1454.

McDonald, M.A., Webb, S.C., Hildbrand, J.A., and Cornuelle, B.D., 1994. Seismic structure and anisotropy of the Juan de Fuca Ridge at $45^{\circ} \mathrm{N}$. J. Geophys. Res., 99:4857-4873.

Nehlig, P., 1993. Interactions between magma chambers and hydrothermal systems: oceanic and ophiolitic constraints. J. Geophys. Res., 98:1962119633.
Patterson, M.S., 1978. Experimental Rock Deformation: New York (Springer-Verlag).

Phillips, W.J., 1972. Hydraulic fracturing and mineralization. J. Geol. Soc. London, 128:337-359.

Pollard, D.D., and Aydin, A.A., 1988. Progress in understanding jointing over the past century. Geol. Soc. Am. Bull., 100:1181-1204.

Ramsay, J.G., 1980. The crack-seal mechanism of rock deformation. Nature, 384:135-139.

Robinson, P.T., Flower, M.F.J., Swanson, D.A., and Staudigel, H., 1979 Lithology and eruptive stratigraphy of Cretaceous oceanic crust, western Atlantic Ocean. In Donnelly, T., Francheteau, J., et al., Init. Repts. DSDP, 51-53, Part 2: Washington (U.S. Govt. Printing Office), 15351556.

Rudnicki, J.W., Yin, J., and Roeloffs, E.A., 1993. Analysis of water level changes induced by fault creep at Parkfield, California. J. Geophys. Res. 98:8143-8152.

Rummel, F., 1987. Fracture mechanics approach to hydraulic fracturing stress measurements. In Atkinson, B.K. (Ed.), Fracture Mechanics of Rock: New York (Academic Press), 317-340.

Secor, D.T., 1965. Role of fluid pressure in jointing. Am. J. Sci., 363:633646.

Scholz, C.H., 1990. The Mechanics of Earthquakes and Faulting: New York (Cambridge Univ. Press).

Sibson, R.H., 1981a. Fluid flow accompanying faulting: field evidence and models. In Simpson, D.W., and Richards, P.G. (Eds.), Earthquake Prediction: An International Review. Maurice Ewing Ser. 4: Washington (Am. Geophys. Union), 593-603.

, 1981b. Controls on low-stress hydro-fracture dilatancy in thrust, wrench and normal fault terrains. Nature, 389:665-667.

- 1985. Stopping of earthquake ruptures at dilational jogs. Nature, 316:248-251.

-1986. Brecciation processes in fault zones: inferences from earth quake rupturing. Pure Appl. Phys., 124:159-175.

-1987. Earthquake rupturing as a mineralizing agent in hydrothermal systems. Geology, 15:701-704.

Smart, P.L., Palmer, R.J., Whitaker, F., and Wright, V.P., 1987. Neptunian dikes and fissure fills: an overview and account of some modern examples. In James, N.P., and Choquette, P.W. (Eds.), Paleokarst: New York (Springer-Verlag).

Toomey, D.R., Solomon, S.C., Purdy, G.M., and Murray, M.H., 1985. Microearthquakes beneath the median valley of the Mid-Atlantic Ridge near $23^{\circ} \mathrm{N}$ : hypocenters and focal mechanisms. J. Geophys. Res., 90: 5443-5458.

Twiss, R.J., and Moores, E.M., 1992. Structural Geology: New York (W.H. Freeman and Co.).

Young, A., 1972. Slopes: Edinburgh (Oliver and Boyd).

Date of initial receipt: 18 August 1994

Date of acceptance: 28 February 1995

Ms 148SR-132 